\title{
III. Zur Theorie und Praxis des politischen Liberalismus in Frankreich vor dem Ersten Weltkrieg
}

\section{Liberalismus in Frankreich nach 1870: Von der Gründungs- phase der Dritten Republik bis zur Jahrhundertwende}

Anders als etwa in Deutschland, wo mit der Reichsgründung zwar das demokratische Männerwahlrecht eingeführt wurde, von echter Parlamentarisierung jedoch nach wie vor keine Rede sein konnte1, kehrte man in Frankreich im Jahr 1870 nicht nur zum erstenmal seit 1852 zur republikanischen Staatsform zurück. Vielmehr wurde das de facto bereits unter dem Zweiten Kaiserreich wieder eingeführte allgemeine Wahlrecht ${ }^{2}$ durch ein modernes parlamentarisches System ergänzt. Diese spezifische historische Ausgangslage bot dem politischen Liberalismus $^{3}$ in seinen verschiedenen Ausprägungen ein ungemein breites Betätigungsfeld und förderte insbesondere seine parlamentarische Ausdifferenzierung in eine nur schwer überschaubare und bislang lediglich für die Frühphase der Republik bis 1875 genauer untersuchte Fülle von politischen Gruppierungen und Meinungsspektren. ${ }^{4}$ Dabei bestimmte ein nicht gering zu veranschlagendes Maß an Kontinuität über den Wechsel der Staatsform hinweg zumindest in der ersten Phase nach der Republikgründung das Gesicht „liberaler“ Politik. So überdauerte der in seiner Tradition bis in die Juli-Monarchie zurückreichende konservative, der konstitutionellen Monarchie zuneigende Liberalismus nicht von ungefähr bis weit in die Konsolidierungsphase der Republik hinein. Erst mit dem Zurücktreten der ihn im wesentlichen tragenden Notabeln aus den führenden Positionen und dem

1 Die Besonderheit des deutschen Falles hebt hervor: Dieter Langewiesche, Deutscher Liberalismus im europäischen Vergleich: Konzeption und Ergebnisse, in: Ders. (Hg.), Liberalismus im 19. Jahrhundert, S. 11-19, hier: S. 14; zum verfassungsrechtlichen Hintergrund: Hans Boldt, Deutsche Verfassungsgeschichte. Politische Strukturen und ihr Wandel. Band 2: Von 1806 bis zur Gegenwart, München 21993, S. 168-184.

Einen allgemeinen Vergleich zwischen deutschem und französischem Liberalismus vor dem Ersten Weltkrieg bietet auch: Hartmut Kaelble, Nachbarn am Rhein. Entfremdung und Annäherung der französischen und deutschen Gesellschaft seit 1880, München 1991, S. 59-86.

2 Die Verfassung des zweiten Empire von 1852, ergänzt durch ein Ausführungsdekret vom 2. Februar 1852, hatte die Rückkehr zum allgemeinen Wahlrecht bestimmt, das bereits durch die Zweite Republik 1848 eingeführt, durch das Gesetz vom 31. Mai 1850 jedoch starken Beschränkungen unterworfen worden war (Raymond Huard, Le suffrage universel en France (1848-1946), Paris 1991, S. 69-100).

3 Zur Forschungs- und Literaturlage hinsichtlich des französischen Liberalismus vgl. Kap. I dieser Arbeit.

4 Vgl. Rainer Hudemann, Fraktionsbildung im französischen Parlament. Zur Entwicklung des Parteiensystems in der frühen Dritten Republik (1871-1875), München 1979. 
Einschwenken eines Großteils der Orleanisten ins republikanische Lager formierte sich im Verlauf der 1880er Jahre eine "neue“ liberale Bewegung. Deren personelle Zusammensetzung und Programmatik hatten sich entsprechend den veränderten Gegebenheiten innerhalb des demokratisch organisierten Verfassungsstaates gewandelt. Um 1880 umfaßte sie im wesentlichen ein politisches Spektrum, das vom rechten Flügel der Radicaux über die bürgerlichen, liberalen Republikaner bis zu den ehemals orleanistischen "Vernunftrepublikanern“ im "Centre gauche" reichte. ${ }^{5}$

Auf parlamentarischer Ebene, wo sich nach Zusammentreten der Nationalversammlung im Februar 1871 bereits die ersten Fraktionen konstituiert hatten, sammelten sich Abgeordnete liberaler Tendenz auf der Linken in der „Gauche républicaine" um die führenden Politiker Grévy, Ferry und Simon sowie in der nicht ganz zu Recht als Sammelbecken der Radikalen des Empire angesehenen „Union républicaine“. Diese wurde bereits vor der Spaltung des Radikalismus 1879 allmählich mehr und mehr von dessen republiktragendem Flügel unter Gambetta dominiert, der seit 1876 durch seine politischen Gegner als „opportuniste“ verunglimpft wurde.6 Innerhalb der Gesamtheit des „parti républicain“, also der republikanisch gesinnten Deputierten der Kammer, wurde diese Fraktion ab 1881 zur stärksten Kraft. Sie vereinte vorwiegend Abgeordnete einer Politikergeneration von oft aus einfachen Verhältnissen aufgestiegenen „homines novi“, die insbesondere nach der Abspaltung des sozialistisch geprägten Flügels unter Louis Blanc und Ledru-Rollin in Abgrenzung von der extremen Linken eine dezidierte Politik zugunsten des mittleren Bürgertums vertraten. Man forderte Kontrollmechanismen sowohl gegen schrankenlosen Wirtschaftsliberalismus wie gegen den wachsenden Einfluß des "Großkapitals“ und favorisierte die Idee der Gewerkschaftsfreiheit. Die politischen Unterschiede zur benachbarten "Gauche républicaine“ manifestierten sich - wie allgemein mindestens in der Frühphase parlamentarischer Organisation in der Dritten Republik - weniger in Form klarer und bindender programmatischer Aussagen, sondern in der Regel im ganz konkreten politischen Vorgehen der Fraktionen und, wie in diesem speziellen Fall, in der Sozialstruktur der Gruppen.7 Dominiert von Parlamentariern, die dem wohlhabenden, alteingesessenen Bürgertum entstammten, zeigte sich die "Gauche républicaine“

${ }^{5}$ Dieser Aufriß orientiert sich an dem Versuch einer systematisierenden Gesamteinschätzung des französischen Liberalismus im 19. Jahrhundert bei Hudemann, Politische Reform, S. 332-352, hier: S. 339-342 sowie dessen Analyse der Kammerfraktionen für die Jahre 1871-1875: Ders., Fraktionsbildung, bes. S. 32-109 und 142-148. Zur politischen Kräfteverteilung ab 1880 vgl. auch: Pierre Lévêque, Histoire des forces politiques en France. Band 2: 1880-1940, Paris 1994, S. 7-29.

6 Die Frage, ob und ab wann die Radikalen dem Liberalismus zuzuordnen seien, hat bislang sehr verschiedene Beantwortung erfahren: Während Jardin den Radikalismus ohne weitere Erläuterungen bereits seit dem zweiten Empire einbezieht, schlägt Hudemann aufgrund der Beobachtung seines politischen Verhaltens eine Zurechnung erst ab Beginn der 80er Jahre vor, während Krumeich noch für die Zeit unmittelbar vor dem Ersten Weltkrieg eher die fortbestehenden Unterschiede betont und die Vorkriegsradikalen als „Partei der bürgerlichen Linken“ mit starken „zentristischen“ Neigungen versteht (Jardin, Libéralisme; Hudemann, Politische Reform, S. 332 und 341; Krumeich, Liberalismus, S. 365, Anm. 5).

7 Für die Zeit ab 1880: Lévêque, Forces politiques II, S. 8f.; für die Phase bis 1875: Hudemann, Fraktionsbildung, S. 36-48, 143 f. Eine pertinente Analyse der Struktur der beiden Fraktionen „Union républicaine" und "Gauche républicaine" bietet Pierre Sorlin: Sorlin, Waldeck-Rousseau, S. 191198. Aufgrund des ergebnislosen Vergleichs der programmatischen Âßerungen beider Gruppierungen reduziert er allerdings die Unterschiede allein auf die soziale Herkunft der Mitglieder. 
skeptischer gegenüber allem staatlichen Interventionshandeln, sei es auf politischem, wirtschaftlichem oder sozialem Gebiet. Sie vertrat eine „liberal-bürgerliche, laizistisch geprägte Republik" und mißtraute insbesondere dem populistischen Vorgehen Gambettas. ${ }^{8}$

Das eigentliche Zentrum der Kammer, hervorgegangen aus einer Gruppe liberal-konservativer Politiker, die sich während der Endphase des Kaiserreichs als oppositionelle „Union libérale“ um ihren Wortführer Thiers organisiert hatten, spaltete sich bis 1873 in zwei konkurrierende Lager, die sich ihrerseits mehrfach in programmatisch nurmehr schwer zu differenzierende Fraktionen teilten. $\mathrm{Zu}$ nächst war man in der „Union libérale“ ab 1869 noch gemeinsam unter anderem für die Dezentralisierung der französischen Verwaltung und für die Liberalisierung des Wahl- und Presserechts eingetreten. Nach dem Regimewechsel zerfiel die Einheit an der Frage einer möglichen Koalition des "Centre gauche" mit der radikalen Fraktion, die von der rechten Mitte überwiegend abgelehnt wurde. Die Frage der neuen Staatsform spielte bei dieser Entscheidung offenbar eine untergeordnete Rolle. Nachdem die unmittelbare Restauration der Monarchie im Oktober 1873 gescheitert war, arrangierte man sich im "Centre droit" mehrheitlich mit der Republik und arbeitete zusammen mit Teilen der Rechten die verfassungsrechtliche Konstruktion des präsidialen Septennats als Kompromiß- und Übergangslösung für eine eventuelle monarchistische Restauration aus. Das "Centre gauche" andererseits hatte sich bereits von Anbeginn seiner Existenz an mehrheitlich für die republikanische Staatsform ausgesprochen. ${ }^{9}$ Im Hinblick auf die politische oder wirtschaftspolitische Orientierung und die soziale Zusammensetzung ließen die beiden zentristischen Gruppierungen kein klar voneinander unterscheidbares Profil erkennen, sieht man von den erwähnten ausschlaggebenden Vorbehalten des rechten Flügels gegenüber einer Annäherung an die „Repräsentanten der neuen Mittelklassen-Demokratie " um Gambetta ab.10

Dieser französische Liberalismus, wie er sich bis 1890 in seiner parlamentarisch faßbaren Form entwickelt hatte, stand in mehrfacher Frontstellung sowohl gegen die „radikal-egalitäre“, antiparlamentarische Linke, gegen bonapartistische Strömungen und die alte monarchistische wie die neue nationalistische Rechte. ${ }^{11}$ Entsprechend läßt sich ein gemeinsamer Grundkonsens, so wenig er sich in Form eines "Programms" niederschlug und so wenig einheitlich selbst innerhalb organisatorisch isolierbarer Gruppen das politische Verhalten in konkreten Sachfragen war $^{12}$, am ehesten in einer gemeinsamen politischen Kultur finden. Diese blieb in ihrem Kern bis 1940 charakteristisch für die liberale Mitte in Frankreich. In ihr verbanden sich das Bekenntnis zur demokratischen Republik als Ausdruck der Volkssouveränität und der Ideen von 1789 mit der Ablehnung der plebiszitären Form der Demokratie, deren Instrumentalisierbarkeit im autoritären Regime des Kaiserreichs man nur zu gut in Erinnerung hatte. Hinzu trat als konstituierendes

8 Lévêque, Forces politiques II, S. 9; Hudemann, Fraktionsbildung, S. 48-55, Zitat: S. 52.

9 Hudemann, Fraktionsbildung, S. 73-109.

10 Hudemann, Fraktionsbildung, S. 362.

"Hudemann, Politische Reform, S. 341; Zitat: Thomas Nipperdey, Einführung, in: Langewiesche (Hg.), Liberalismus, S. 279-281, hier: S. 280.

12 Vgl. hicrzu das Resümee bei Hudemann, Fraktionsbildung, S. 359-364. 
Element ein unterschiedlich akzentuierter Antiklerikalismus mit Blick auf die anzustrebende Laizisierung des Staates unter Ausschaltung des politischen und sozialen Zugriffs der Kirche. Deren systemstabilisierende Haltung unter dem Ancien Régime, in der Restaurationszeit und unter dem Zweiten Kaiserreich hatte sie in dieser Sicht als republiktragende Kraft disqualifiziert. Einheitlich lehnte man die Idee des Klassenkampfs ab, setzte vielmehr auf eine begrenzte Politik sozialer Verbesserungen unter dem Vorzeichen der Integration divergierender Interessen. In der Umsetzung dieser "großen" Prinzipien dominierte freilich ein eher pragmatisches Vorgehen, das über Gambettas Postulat des stufenweisen, reformerischen Herangehens an die sich stellenden Probleme hinausreichte. Von entschlossener Flexibilität in der Verteidigung der neuen Staatsform zeugen etwa die Milderung der Laizitätspolitik im Hinblick auf eine Annäherung an die „ralliierten“, also zur Republik bekehrten Katholiken zwischen 1896 und 1898; davon zeugen auch die Beschränkungen liberaler Grundrechte, wie sie sich in der Gewährung voller Vereinigungsfreiheit nicht vor 1901, in der gesinnungskritischen Bereinigung des öffentlichen Dienstes zwischen 1877 und 1883 oder der Armee nach 1902 manifestierten. 13

Anders als der deutsche Liberalismus erlebte sein französischer Gegenpart in den siebziger Jahren des 19. Jahrhunderts einen kontinuierlichen Zuwachs an parlamentarischem Gewicht. Dieser ließ zunächst die seit 1885 in ihrer Mehrzahl in der „Union des Gauches“ vereinten „gemäßigten“ Republikaner, die „opportunistes", zur stärksten Kraft werden, bevor ab der Jahrhundertwende die Radikalen die führende Rolle übernahmen. Zusammen verfügten die liberalen Gruppierungen bis zum Ersten Weltkrieg durchgehend über die parlamentarische Mehrheit und stellten sämtliche Regierungschefs. ${ }^{14}$ Das mit dieser Dominanz verbundene innenpolitische Werk - zu umfangreich und vielgesichtig, um es hier einer eingehenden Betrachtung unterziehen zu können - bedingte in seiner Eigenart spezifische Stärken und Schwächen des französischen Liberalismus. Zwar konnten seine Vertreter in Frankreich ebensowenig wie in Deutschland darauf verweisen, daß ein wesentliches Anliegen der liberalen Bewegung, die Nationsbildung, durch sie selbst eingelöst worden war. Hingegen waren anders als in Deutschland die Begründung, der Ausbau und die Festigung nationaler, die neue Staatsform tragender Institutionen und Bewußtseinslagen im Frankreich der Dritten Republik in unvergleichlich stärkerem Maße, ja nahezu ausschließlich das Werk liberaler Politiker. Und wenn wie im wilhelminischen Kaiserreich liberale Grundgedanken insbesondere in ihrer nationalen Ausprägung auch in Frankreich allmählich zu „politischem Allgemeingut "15 wurden, so verlief dieser Prozeß nicht wie in Deutschland zu Lasten des politischen Profils der Liberalen. Er stärkte im Gegenteil ihren Führungsanspruch im Hinblick auf die Vertretung der nationalen und damit spätestens seit 1879 - der republikanischen Sache.16 Bis zur Jahrhundertwende

13 Hierzu im Überblick: Lévêque, Forces politiques II, S. 13-20.

14 Kaelble, Nachbarn am Rhein, S. 66 f.; zu den deutschen Liberalen im Umfeld der Reichsgründung auch: Dieter Langewiesche, Liberalismus in Deutschland, Frankfurt 1988, S. 128-164; für die französische Seite: Lévêque, Forces politiques II, S. 20-25.

15 Langewiesche, Liberalismus in Deutschland, S. 164;

16 Vgl. zum Grundgedanken dieses knappen Vergleichs: Kaelble, Nachbarn am Rhein, S. 66-69. 
war diese Verankerung der demokratischen Republik bereits weit vorangeschritten, und zwar nicht nur auf institutioneller Ebene, sondern auch im Bereich der politischen Mentalitäten: das demonstrierte die erfolgreiche Abwehr der Republikgegner von links und rechts im Verlauf der Boulanger-Krise 1887-1889 oder auch die Bewältigung der schwersten Krise der Konsolidierungsphase, der Dreyfus-Affäre.

Andererseits zeigte es sich, daß eben jene Rolle der „regierenden Partei“ und der damit verbundene Zwang zur Bewährung in der Verantwortung das Ansehen der Liberalen stärker kompromittieren, auch die Schwächen der Doktrin deutlicher zutage treten lassen konnte, als dies bei gezwungenermaßen in der Opposition verharrenden Gruppierungen nach deutschem Muster möglich war. Die zumindest anfängliche Konzeptlosigkeit in der Reaktion auf die sozialpolitische Herausforderung durch die aufkommende Arbeiterbewegung, welche in die teils blutige Niederschlagung von Streikbewegungen mündete, wurde bereits von den Zeitgenossen als eines von vielen Anzeichen für eine Anpassungskrise des Liberalismus erkannt. Modelle zur Bewältigung dieser sozialen Frage wurden in politiknahen Kreisen von Intellektuellen, Industriellen und Sozialwissenschaftlern vorwiegend liberaler Orientierung entwickelt. ${ }^{17}$ Sozialphilosophen und Soziologen überdachten daneben in allgemeinerer Weise das Verhältnis von Individuum und Gesellschaft neu, stellten insbesondere heraus, daß die Ausweitung staatlicher Einflußsphären nicht zwangsläufig mit der Verminderung persönlicher Freiheit einhergehen mußte. ${ }^{18}$ Damit wurden die theoretischen Grundlagen gelegt für die allmähliche Abkehr der französischen Liberalen von der Maxime staatlicher Nichtintervention im gesellschaftlichen Bereich und für die zaghafte Ausbildung erster Ansätze des bürgerlichen Wohlfahrtsstaates. ${ }^{19}$ Die anvisierten Reformpläne blieben jedoch vor 1914 im wesentlichen unverwirklicht, die staatliche Sozialgesetzgebung im Vergleich etwa zur Bismarckschen Arbeitsschutz- und Sozialpolitik rudimentär. ${ }^{20}$

Die Neujustierung des politischen Standorts der "gemäßigten“, also nicht-radikalen, liberalen Republikaner ab Beginn der neunziger Jahre, die bei weitgehend gleichbleibender personeller Zusammensetzung die Bezeichnung "opportunistes“ zugunsten von "progressistes" abzulegen begannen, vollzog sich dann auch nicht auf philosophisch-theoretischem, sondern auf politisch-praktischem Gebiet. Die Bildung der Regierung Waldeck-Rousseau im Juni 1899 unter dem Vorzeichen der „Défense républicaine“ war nicht zuletzt Ausdruck einer Neuformierung der liberalen Kammermehrheit in Reaktion auf die vorangegangene, fortgesetzte Rechtstendenz "progressistischer" Regierungen. Getragen von Ministern so unterschiedlicher politischer Herkunft wie dem Sozialisten Millerand oder General

17 Vgl. hierzu Sanford Elwitt, The Third Republic Defended. Bourgeois Reform in France, 18801914, Baton Rouge/London 1986.

18 William Logue, From Philosophy to Sociology. The Evolution of French Liberalism, 1870-1914, DeKalb/Illinois 1983, hier: S. 217.

19 Logue, Philosophy to Sociology, S. $10 \mathrm{f}$.

20 Beispiele staatlicher Sozialgesetzgebung in Frankreich vor 1914 finden sich bei Léon Duguit, Traité de droit constitutionnel. Band I, Paris 1921, S. 142 f.; es bietet eine umfassende Gesamteinschätzung: Judith F. Stone, The Search for Social Peace. Reform Legislation in France, 1890-1914, Albany 1985. 
Galliffet, fand Waldecks Kabinett die Unterstützung der Radikalen, eines Teils der Sozialisten und all jener „progressistes“ um Poincaré, Jonnart und Barthou, die die allzu unentschlossene Haltung der Regierung Dupuy angesichts der nationalistischen Attacken gegen die Republik im Gefolge der Dreyfus-Affäre zu größter Besorgnis veranlaßt hatte. ${ }^{21}$ Die entschlossen laizistische, anti-nationalistische Politik Waldeck-Rousseaus führte zur Spaltung der „progressistes“ und zur Gründung der wichtigsten Gruppierung des nicht-radikalen Liberalismus in Frankreich vor 1940, der „Alliance Républicaine Démocratique“.

\section{Die „Alliance Républicaine Démocratique“: Ihre Entwicklung bis zum Ersten Weltkrieg}

Die liberale Bewegung Frankreichs organisierte sich erst im Zuge der Neuformation der politischen Kräfte des Landes zu Beginn des zwanzigsten Jahrhunderts in politischen Parteien, welche gleichzeitig die ersten Vereinigungen dieser Art in Frankreich darstellten. Diese liberalen Parteigründungen waren Teil einer Gründungswelle, die nahezu das gesamte politische Spektrum im europäischen Vergleich relativ spät erfaßte. Nicht zufällig konstituierten sich im gleichen Zeitraum der „Parti socialiste, Section française de l'Internationale ouvrière“ (1905) und die bald bedeutendste konservative Partei der Dritten Republik, die „Fédération Républicaine“ (1903). Formale Grundlage und konkreten Auslöser dafür bildete insbesondere die Aufhebung der restriktiven Praxis des Vereinigungsrechts des Empire, nachdem ein Gesetz vom 1. Juli 1901 die Bildung nicht-religiöser Vereinigungen ohne die vorherige Genehmigung durch die Behörden ermöglicht und staatliche Unterstützung in Aussicht gestellt hatte.22

So kam es im Vorfeld der Parlamentswahlen des Jahres 1902 zur Gründung des „Parti républicain, radical et radical-socialiste“, der sich in Anknüpfung an „radikalistische" Strömungen des 19. Jahrhunderts im Juni 1901 als programmatisch und organisatorisch locker konzipierte Interessenvertretung des selbständigen Kleinbürgertums zusammenfand. ${ }^{23}$ Im Mai des gleichen Jahres hatte sich mit der "Alliance Républicaine Démocratique “ bereits eine Gruppierung konstituiert, die ebenfalls mit Blick auf die anstehenden Wahlen als bürgerliche Sammlungspartei zwischen den linksliberalen "Radicaux“ und der republikfeindlichen Rechten gedacht war und sich als Vertretung großbürgerlicher Belange verstand. ${ }^{24}$ Die Bildung einer Mitte-Rechts-Formation lag insbesondere deshalb nahe, da mit der Spaltung der „Opportunistes“ im Gefolge der Dreyfus-Affäre das bisherige Sam-

21 Mayeur, Troisième République, S. 161-186; Lévêque, Forces politiques II, S. 20-26.

22 Zur Loi du 1er Juillet 1901 vgl. Adhémar Esmein, Eléments du droit constitutionnel français et comparé. Band II: Le droit constitutionnel de la République française, Paris ${ }^{8} 1928$, S. 640-648. Olivier Martin, Les institutions et les lois de la Troisième République, Paris 1936, S. 12.

23 Berstein, Parti Radical I, S. 35-49; zum französischen Parteiensystem zwischen den Kriegen immer noch grundlegend: Rudolf von Albertini, Parteiorganisation und Parteibegriff in Frankreich, in: HZ 193 (1961), S. 529-600, hier: S. 572-582.

24 Zur Entstehungsgeschichte der Partei: Albertini, Parteiorganisation, S. 582-585; Wileman, L'Alliance, S. 8-20. Vgl. zur Literaturlage hinsichtlich der „Alliance Républicaine Démocratique“ das Einleitungskapitel dieser Arbeit. 
melbecken des französischen Rechtsliberalismus entscheidend geschwächt worden war. So fungierte als parlamentarischer Träger und personeller Kern der neuen Parteigründung nicht von ungefähr eine Gruppe von 115 ehemaligen „opportunistischen" Abgeordneten: Sie hatten sich am Höhepunkt der Affäre für die Unterstützung der zur Durchsetzung einer schiedlichen Lösung entschlossenen, sozialreformerischen Regierung Waldeck-Rousseau und deren Programm der „Défense républicaine" entschieden. Entsprechend sprach man sich in der Präambel des ersten offiziellen Parteiprogramms gleichermaßen gegen „kollektivistische Utopien" von links wie für soziale Reformen aus und grenzte sich andererseits klar gegen die Widersacher der Republik von rechts ab.25 Mit der Berufung auf Waldeck-Rousseau, dessen politisches Reformwerk von Anbeginn einen konstituierenden Teil des Selbstverständnisses der neuen Gruppierung darstellte - man nahm für sich in Anspruch, jene große republikanische Partei ins Leben gerufen zu haben, die dieser anläßlich eines Banketts in Toulouse angeregt hatte ${ }^{26}-$, ging die Übernahme der liberalen Losung "ni réaction ni révolution“ einher, wie sie seit Jules Ferry zum Kernbestand des politischen Credos der „modérés“ gehörte. In den ersten programmatischen Überlegungen der Partei vom Oktober 1901 findet sich dieser Grundsatz ausgeführt: Ziel sei die Herstellung und Sicherung der „République ordonnée et libérale, respectueuse de tous les droits, basée sur une justice égale pour tous; anticollectiviste mais constamment et passionnément préoccupée du progrès social; antinationaliste mais jalouse gardienne de l'honneur et de la puissance de la patrie; anticléricale mais non antireligieuse; vraiment démocratique, sagement et profondément réformatrice". ${ }^{27}$

Dieser im republikanischen Lager zwischen Sozialisten und rechten Republikgegnern allgemein konsensfähige Katalog an politischen Zielen - Verteidigung der liberalen Republik, Antikollektivismus, sozialer Fortschritt, gemäßigter Nationalismus und Laizität - zeigt klar den Anspruch der „Alliance“ auf Vertretung einer weitgefaßten politischen Mitte. - Ein Anspruch, der indes nicht ohne Berücksichtigung der zweiten, nahezu gleichzeitig erfolgten republikanischen Parteigründung einzulösen war. Er begründete vielmehr eine dauerhafte Konkurrenzsituation mit dem Parti Radical um die Besetzung des mittleren Spektrums im politischen System Frankreichs. Diese nahm bis zum Ende der Dritten Republik zwar in variierender Gestalt von Abgrenzungs- und Annäherungsbemühungen Form an, blieb jedoch ein Leitmotiv des Verhältnisses zwischen den zentristischen Gruppen. ${ }^{28}$ Die beiden Gründungen und das damit verbundene Bemühen um parteipolitische Sammlung aller republikanischen Kräfte entsprachen zweifellos zu allererst der Sorge, den organisatorischen Anstrengungen der Linken entgegenzu-

25 Vgl. hierzu das Exemplar einer ausgearbeiteten Programmschrift der Alliance vom 8. August 1907 (Bibliothèque Nationale (BN), papiers Alliance Républicaine Démocratique, Carton 1); dazu auch: Wileman, L'Alliance, S. 20.

26 Ebenda.

27 Zitiert nach Sanson, Centre et Gauche, S. 498. Der insbesondere in Wahlkampfzeiten oft wiedergegebene Text findet sich leicht verändert auch bei Lachapelle, L'Alliance démocratique, S. 19. Vgl. hierzu außerdem: Krumeich, Liberalismus, hier: S. 358f.

28 Für die ersten eineinhalb Jahrzehnte des 20. Jahrhunderts stellt die Problematik des Anspruchs der liberalen Strömungen auf Besetzung des politischen Zentrums im Überblick dar: Krumeich, Liberalismus. Die These von der engen Abhängigkeit der "Alliance“ in ihrer politischen Selbstdefinition und Praxis vom Parti Radical entfaltet auch Sanson, Centre et Gauche. 
treten, die mit der Jahrhundertwende den entscheidenden Rückschlag des gescheiterten Kommuneaufstandes überwunden hatte. Doch manifestierte sich im $\mathrm{Zu}$ sammenschluß der „Alliance Républicaine Démocratique“ darüber hinaus zugleich die Furcht vor der völligen Absorption der schlecht organisierten „modérés" durch die radikalsozialistische Partei. Erhob diese doch den Anspruch, maßgeblicher „parti républicain“ zu sein, was auch darin zum Ausdruck kam, daß man die Figur Waldeck-Rousseaus bereits symbolträchtig in den eigenen Gründungsmythos eingefügt hatte. ${ }^{29}$

Organisatorisch konnte bei der Gründung der „Alliance“ wie auch bei derjenigen des Parti Radical auf bereits bestehende Strukturen zurückgegriffen werden, die bis dahin nur auf der Ebene von Wahlkreisen und als jeweils ad hoc sich zusammenfindende Wahlkomitees in Erscheinung getreten waren. ${ }^{30}$ Unterschiede blieben allerdings bestehen: Zwar war der Parti Radical bis zum Vorabend des Ersten Weltkrieges noch weit von einer effektiv organisierten, kohärenten und programmatisch klar konturierten Massenpartei entfernt, doch zeigte er sich immerhin über seine lokalen Komitees fest im Land verankert; die Pariser Parteizentrale unternahm ernsthafte Anstrengungen zur einheitlichen Leitung. ${ }^{31}$ Dagegen hat die "Alliance" in der gleichen Periode weder im Hinblick auf die Mitgliederbasis oder die Parteistruktur noch die Durchsetzung eines einheitlichen Führungswillens oder die Kontinuität der Parteiarbeit je den Charakter einer im wesentlichen auf die Wahlvorbereitung ausgerichteten Honoratiorenpartei verloren.

So bildete die tragende personelle Schicht weniger der Typus des "militant“, der die Stärke der sozialistischen Gruppierungen und des Parti Radical ausmachte. Auch fehlte jene enge Verflechtung mit Freimaurerlogen, die der radikalen Partei in den ersten Jahren ihrer Existenz wirksamen Ersatz für die fehlende Massenbasis und das schwach ausgeprägte institutionelle Gerüst geboten hatte, wenngleich insbesondere zu den Führungsgremien der "Alliance“ personelle Verbindungen bestanden. ${ }^{32}$ Vielmehr stützte sich die Partei im wesentlichen auf das Engagement lokaler Notabeln, welche ihrerseits nicht gewillt waren, zentrale Parteiinstanzen aufzubauen, die ihre politische Handlungsfreiheit wesentlich zu beschränken imstande waren. ${ }^{33}$

29 Zur organisatorischen Sammlung der Linken als Anstoß für die Gründung der „Alliance“: Wileman, L'Alliance, S. $15 \mathrm{f}$. Zur Konkurrenz mit den "Radicaux" vgl. Berstein, Troisième République, S. 22. Zum Anspruch des Parti Radical auf die Vorläuferschaft Waldeck-Rousseaus: Berstein, Parti Radical I, S. 39 und 41 f.; auf Sammlung aller republikanischen Kräfte und auf den Titel „parti républicain“: Ebenda, S. 42 f. Zu den Gründungsmotiven der "Alliance“ insgesamt auch: Sanson, Centre et Gauche, S. 499.

30 Zum Parti Radical: Berstein, Parti Radical I, S. 33-35. Zur „Alliance“, doch ohne genauere Angaben: Wileman, L'Alliance, S. 16.

31 Zu den organisatorischen Fortschritten des Parti Radical bis 1914: Berstein, Parti Radical I, S. 41, $45 f$., 47, 73-75.

32 Zur Verbindung des Parti Radical mit den „Franc-Maçons“: Berstein, Parti Radical I, S. 47-49; Albertini, Parteiorganisation, S. 584. Rosemonde Sanson hat herausgestellt, daß unter den Gründungsmitgliedern der "Alliance" ein Anteil von $26 \%$ mit Sicherheit den Freimaurern zuzuordnen war; im Ehrenkomitee, das die Patronage der Kandidaten der Partei für die Parlamentswahlen von 1902 betrieb, figurierten über 40\% Logenmitglieder! (Sanson, Centre et Gauche, S. 501).

33 Wileman, L'Alliance, S. 17. Albertini, Parteiorganisation, S. 583 f. Solange die Mitgliederkartei der "Alliance" der Forschung nicht zugänglich ist - der einschlägige Karton 1 der „Papiers Alliance Républicaine Démocratique“ ist bis auf weiteres für die Benutzung gesperrt - müssen Einschätzungen der Mitgliederstruktur notwendig indiziengestützte Vermutungen bleiben. 
In der für Honoratiorengruppierungen typischen Weise kam die Auswahl der Parteiführung nicht durch einen „basisdemokratischen“ Akt der Mitglieder zustande. Lediglich das 250 Mitglieder umfassende "Comité directeur" wurde durch die jährliche Mitgliederversammlung - die „Assemblée générale“ - auf vier Jahre direkt gewählt. Das eigentlich leitende Parteigremium, die 35 Mitglieder umfassende "Commission centrale exécutive“, der die alltägliche Geschäftsführung oblag, wurde hingegen durch Kooptation aus den Reihen des "Comité directeur" bestimmt. Das Präsidium der Partei besetzten erfahrene Politiker, die teils bereits vor ihrem Eintritt in die "Alliance" weitreichende parlamentarische und ministerielle Erfahrung ebenso wie politisches "standing" erworben hatten: Louis Barthou, Paul Doumer, Raymond Poincaré, nach dem Ersten Weltkrieg schließlich Pierre-Etienne Flandin und Paul Reynaud. ${ }^{34}$

Auf der wichtigen Ebene zwischen lokalen Komitees und den Pariser Zentralgremien, auf der Stufe von Arrondissements und Départements, war die Struktur der Partei nur schwach ausgeprägt. Versuche zur dauerhaften Begründung von Wahlkreisorganisationen blieben vor 1914 offenbar auf die Anfangszeit der Partei und insbesondere das Umfeld der Wahlen von 1902 beschränkt. Zwischen 1904 und dem Beginn der dreißiger Jahre dagegen stand der Aufbau einer effektiven und schlagkräftigen Basisorganisation nicht im Mittelpunkt der Aktivitäten. Als man nach 1933 unter Parteichef Flandin ernsthafte Anstrengungen dazu unternahm, blieb das Ergebnis enttäuschend. ${ }^{35}$ Die "Alliance" behielt vielmehr den Charakter eines losen Zusammenschlusses zur propagandistischen und logistischen Unterstützung ihrer Kandidaten vorwiegend in Wahlkampfzeiten, konnte allerdings selbst diesem beschränkten Anspruch nicht immer gerecht werden. So mußte noch im Jahre 1926 Paul Reynaud die bittere Erfahrung machen, daß seine Partei nicht einmal in Paris über eine vernetzte und geeinte Organisation verfügte, obwohl formal durchaus eine Vielzahl von Komitees und ehrenamtlichen Helfern zur Verfügung stand. ${ }^{36}$

Diese geringe Beachtung der Organisationsfrage über Jahrzehnte hinweg kann nur verstanden werden aus der konkreten Entstehungssituation der Partei und der politischen Mentalität ihrer Mitglieder. Organisationshemmende theoretische Faktoren verbanden sich hier mit solchen psychologischer oder wahltaktischer Art und verhinderten die Ausbildung straffer Strukturen, verknüpft mit kontinuierlicher Mitgliederwerbung oder energischer politischer Schulungs- und Propagandatätigkeit. ${ }^{37}$ Anders als etwa die tragende Schicht der zur gleichen Zeit sich neu formierenden Arbeiterbewegung besaßen die Initiatoren der „Alliance“ - wie gesehen - im allgemeinen bereits gesicherten politischen Einfluß, ja zum großen

34 Zur Organisation der Führungsgremien in der „Alliance“: Albertini, Parteiorganisation, S. $583 \mathrm{f}$.

35 Albertini, Parteiorganisation, S. 583; Wileman, L'Alliance, S. 27-34; Audigier, L'Alliance démocratique.

36 Bericht der Sûreté über eine Rede Reynauds im Kreis seiner Parteifreunde, 3.4. 1926 (AN, $\mathrm{F}^{7}$ 13254); vgl. dazu ausführlich Kapitel VI dieser Arbeit.

37 Eine Untersuchung, die die Entstehung und frühe Gestalt der Parteien der politischen Mitte Frankreichs im Hinblick auf organisatorische, weltanschauliche und praktisch-politische Bedingungsfaktoren umfassend analysieren würde, liegt bislang nicht vor. Vgl. hingegen: Raymond Huard, La naissance du parti politique en France, Paris 1996. 
Teil sogar ein Abgeordnetenmandat. ${ }^{38}$ So entstand die Partei nicht primär zur Eroberung der politischen Macht und überdies nicht außerhalb des Parlaments, sondern als Unterstützungsorganisation, deren Ursprünge im Parlament lagen und deren Wirken auf den Machterhalt im Rahmen der parlamentarischen Vertretung ausgerichtet blieb. Der Aufbau eines national tätigen Agitations- und Parteiapparates machte nicht das Hauptinteresse der führenden Mitglieder aus, da sie sich in der Regel ja bereits auf eine feste Wählerklientel in ihrem Wahlkreis, auf die Unterstützung zumindest eines Teils der lokalen Presse und diejenige ihrer Komitees stützen konnten. Zudem konnte die systematische Erweiterung der Parteibasis nicht im Interesse von Politikern liegen, deren Vereinigungsziel zuvörderst in der parlamentarischen Elitenbildung bestand: Von einer Erhöhung der Mitgliederzahl hatten sie vor allem die verstärkte innerparteiliche Konkurrenz um Einfluß und Positionen zu befürchten.

$\mathrm{Daß}$ sich andererseits die bestehenden lokalen Strukturen nicht wie die in Deutschland zur gleichen Zeit existierenden Honoratiorengruppen schon allein aus ganz praktischen Gründen der Koordination mit Nachbarkomitees oder der Absprache mit anderen Gruppierungen allmählich von der Basis her zu Parteiorganisationen verfestigten ${ }^{39}$, ist in hohem Maße auf den Parteibegriff der liberalen Formationen und der sie tragenden Schichten zurückzuführen. In „vorparteilicher" Zeit verwurzelt und in seinen Grundzügen bis ins 20. Jahrhundert fortwirkend, gingen in ihm die durch die Französische Revolution begründete politische Tradition und daran anschließende theoretische Überlegungen zum Wesen des repräsentativen Systems eine enge Verbindung ein. Aus dem Zusammenspiel mit der allgemeinen, individualistisch geprägten Disposition des liberalen Bürgertums als wichtigstem Träger der liberalen Bewegung seit Mitte des 19. Jahrhunderts, seinem Mißtrauen gegenüber der Politisierung breiter Massen ${ }^{40}$ entwickelten sich so die Grundzüge einer politischen Mentalität, die sich als genügend resistent erwies, um Bemühungen zur Bildung homogener Massenparteien im mittleren politischen Spektrums Frankreichs während der Dauer der Dritten Republik scheitern zu lassen.

Dabei hatte sich der „wesentlich negativ[e]“41 Parteibegriff der Revolutionszeit durchaus in Richtung einer positiveren Interpretation fortentwickelt. Bereits nach 1815 wurde er durch einzelne Stellungnahmen wichtiger Staatstheoretiker wie Benjamin Constant und Duvergier de Hauranne aufgewertet, die geneigt waren, Parteien als nützlichen Teil des parlamentarischen Systems zu interpretieren. Daneben aber kam es zunächst noch weder zu Versuchen der theoretischen Fundierung des Parteienwesens noch zur Fortschreibung von Ansätzen zur Bildung na-

38 Die seit 1905 in der „S.F.I.O.“ vereinigten Sozialisten besaßen im Jahr 1902 erst 14 Abgeordnete, im Jahr 1906 deren 20, dies bei einer Gesamtzahl von Parlamentariern in der „Chambre des Députés“, die etwa bei 600 lag (Maurice Duverger, Le système politique français. Droit constitutionnel et systèmes politiques, Paris 181985, S. 113).

39 Vgl. zur Situation in Deutschland: Thomas Nipperdey, Die Organisation der bürgerlichen Parteien in Deutschland vor 1918, in: HZ 185 (1958), S. 550-602, hier: S. 559-563; Ders., Die Organisation der deutschen Parteien vor 1918, Düsseldorf 1961, S. 42-54, $86 \mathrm{ff}$.

40 Zur Schwierigkeit, insbesondere die Trägerschichten der rechtsliberalen Parteien auf eine ausgeprägte Gruppensolidarität zu verpflichten, vgl. Albertini, Parteiorganisation, S. 583.

41 Albertini, Parteiorganisation, S. 546. 
tionaler Wahlorganisationen, die sich im Vorfeld der Revolution von 1830 bereits gezeigt hatten. Initiativen einzelner Politiker wie die vergeblichen Bemühungen Gambettas zur Schaffung einer homogenen republikanischen Partei als Stütze einer stabilen Regierungsmehrheit blieben Ausnahmefälle. Vielmehr behielt auch im veränderten Kontext das Repräsentationsmodell der Großen Revolution einen Gutteil seiner Wirkkraft. In seinem Rahmen aber wurden politische Parteien als unzulässige Institutionalisierung von Partikularinteressen und als Gefährdung des objektiven Willensbildungsprozesses der Gesamtnation begriffen. Noch zu Beginn des 20. Jahrhunderts dominierte die Skepsis gegenüber wohlorganisierten "corps intermédiaires“ nicht nur in Kreisen der republikfeindlichen Rechten, wo man die Schwächen des Parteiensystems als Angriffspunkt für grundsätzliche Kritik an der „République des Comités“ und am parlamentarischen System schlechthin instrumentalisierte. Selbst in der liberalen Publizistik der Jahrhundertwende äußerte sich unverhohlene Parteienkritik, die teils auf die Notwendigkeit einer klaren Trennung von Staatsgewalt und Gesellschaft unter Verzicht auf Zwischeninstanzen zur Wahrung der Individualrechte abhob, teils die Entscheidungskompetenz des Parlaments durch die Eigendynamik vorparlamentarischer Instanzen gefährdet sah. ${ }^{42}$

Die dennoch allmählich voranschreitende Wandlung des Parteienbegriffs wie auch die Schwierigkeiten eines neuen Verständnisses spiegelten sich in der französischen Staatsrechtslehre der Jahrhundertwende. Hier zeichnete sich durchaus eine vorsichtige Tendenz zur Öffnung gegenüber den Organisationstendenzen im vorstaatlichen Bereich und der Erscheinung der modernen Parteiendemokratie insgesamt ab. So verstand der wichtigste zeitgenössische Staatsrechtstheoretiker, Adhémar Esmein, die Bildung politischer Interessengruppen in der 1906 erschienenen, vierten Auflage seines verfassungsrechtlichen Standardwerkes bereits als "natürlich" und „unvermeidlich“ und empfahl, diese trotz ihrer Mängel als immerhin greifbare und "moralisch verantwortliche" Organisationen hinzunehmen. Bezeichnenderweise beschränkte sich seine Parteienrechtfertigung aber darauf, deren außerparlamentarische Kanalisierungsfunktion hervorzuheben. Mit Blick auf das englische Zweiparteiensystem blieb er bei der Verurteilung der Kammerfraktionierung in eine Vielzahl von "groupes", die er nicht nur als Hindernis für das reibungslose Funktionieren des parlamentarischen Systems und die Bildung großer Parteien, sondern als Hauptursache für die Instabilität der Regierungen überhaupt ausmachte. ${ }^{43}$ Ähnlich gespaltene Zustimmung zeigte der Politologe und Professor an der "Ecole libre des Sciences politiques“, Charles Benoist, hinter dessen grundsätzlicher Parteienrechtfertigung die klassische Kritik an der Verselbständigung des "Apparats" und an der Brechung des Wählerwillens durchschien. Entscheidende Funktion zur Organisation politischer Willensbildung jen-

42 Siehe dazu die Beispiele bei Albertini, Parteiorganisation, S. $566 \mathrm{f}$.

43 Adhémar Esmein, Eléments de droit constitutionnel et comparé, Paris ${ }^{4} 1906$, S. 172 f. und 181185. Diese Sicht Esmeins wurde bis weit in die zwanziger Jahre hinein fortgeschrieben. Zunächst unverändert in der unter gleichem Titel erschienenen 5. Auflage von 1909: S. 198-200; dort inhaltlich entsprechend auch die Kritik an den groupes: S. 210-214. Noch in der 8., durch einen Schüler besorgten Auflage des Werks finden sich die Gedanken übernommen: Ders., Eléments de droit constitutionnel français et comparé. Revue par Henry Nézard, Band I, Paris ${ }^{8} 1927$, S. $262 \mathrm{f}$. und 279-284. Vgl. auch Albertini, Parteiorganisation, S. 561-564 und S. 567 f. 
seits bloßer Lokalinteressen nahmen die entstehenden Parteien dagegen im Werk von Félix Moreau ein, der sie in eine moderne Theorie parlamentarischer Vertretung einbettete und so eine Brücke zwischen Organisationsbestrebungen im gesellschaftlichen Bereich und effektiver Staatsverfassung zu schlagen versuchte. ${ }^{44}$

Wenngleich also in der zeitgenössischen Staatslehre der Weg für ein neues Verständnis bereitet war und durch die Ansätze zu einer „gruppenbezogenen Staatsund Gesellschaftslehre“ im Umkreis von Emile Durkheim, Léon Duguit und Maurice Hauriou weitere Unterstützung fand ${ }^{45}$, blieb das Honoratiorenmodell in der politischen Praxis der gemäßigten bürgerlichen Gruppierungen bis in die III. Republik hinein dominierend. Um 1830 mit Erstarken der liberalen Bewegung ausgebildet, zeigte es seine ganze Beharrungskraft noch im Streit um die Reform des Wahlsystems, der ab 1907 auf nationaler Ebene einsetzte und 1909 Eingang in die Debatten der Chambre des Députés fand. Die Einführung des Verhältniswahlrechts, welche nicht zuletzt die Bildung homogener und überregionaler Parteien impliziert hätte, scheiterte vor dem Ersten Weltkrieg am Widerstand gerade aus Gruppen der parlamentarischen Mitte, insbesondere der radikalen Partei und ihrer Anhänger im Senat. Diese verteidigten mit der Mehrheitswahl neben Zielen der Parteiräson ein System von Ordnungsvorstellungen, worin wesentliche Aspekte des Honoratiorensystems einen zentralen Platz einnahmen, etwa die Kleinräumigkeit der Willensbildung auf Arrondissementsebene und die damit verbundene Wählernähe.46

Auch die „Alliance“ blieb ein „Verband ohne Unteroffiziere und Mannschaften " ${ }^{47}$, dessen Bindekraft gegenüber den eigenen Parlamentariern gering war, wenngleich Aufrufe zur strafferen Führung der Mitglieder bereits seit den ersten Parteikongressen regelmäßig wiederkehrten. So traten ihre Kandidaten bis ins Jahr 1910 in Wahlkämpfen kaum unter dem Parteinamen an ${ }^{48}$, und Doppelmitgliedschaften von Einzelpolitikern, ja ganzen Komitees in der „Alliance“ und insbesondere im Parti Radical waren an der Tagesordnung. Erst 1910 beschloß der Parteikongreß der Radikalen ein Verbot dieser Praxis und trieb damit die bis dahin unvollkommene organisatorische und ideologische Differenzierung beider zentristischer Strömungen einen entscheidenden Schritt voran. ${ }^{49}$ Die Umbenennung der

44 Vgl. etwa Charles Benoist, Comment on capte le suffrage et le pouvoir, in: Revue des Deux Mondes 3 (1904), S. 885 ff.; Ders., Le suffrage universel et l'évolution des partis politiques, in: Revue des Deux Mondes 2 (1904), S. $520 \mathrm{ff}$.

Félix Moreau, Régime parlementaire et principe représentatif, in: Revue politique et parlementaire 27 (1901), S. 331 ff. und 28 (1901), S. 61 ff.; Ders., Précis élémentaire de droit constitutionnel, Paris 71911. Dazu auch: Klaus von Beyme, Die parlamentarischen Regierungssysteme in Europa, München 1970, S. 228 f.; Werner Scherer, Verhältniswahl und Reform der politischen Ordnung. Die Auseinandersetzung um den Proporz in Frankreich bis zur Wahlreform von 1919, Diss. Heidelberg 1982, S. 343-347.

45 Dazu Scherer, Verhältniswahl und Reform, S. 277-315.

+6 Vgl. zur Frage der Wahlrechtsreform in Frankreich vor dem Ersten Weltkrieg allgemein: Scherer, Verhältniswahl und Reform; zu den Argumenten der "Antiproportionalisten" insbesondere die Senatsdebatten vom März 1913 und die sie vorbereitenden Kommissionsstudien: Ebenda, S. 597614.

47 So Nipperdey, Organisation der deutschen Parteien, S. 87 zur Kennzeichnung der Organisationsstruktur der nationalliberalen Partei in Deutschland bis etwa in die neunziger Jahre des 19. Jahrhunderts.

48 Darauf weist wiederholt hin: Wileman, L'Alliance, S. $16 \mathrm{f}$., $33 \mathrm{f}$.

49 Berstein, Parti Radical I, S. 67. 
„Alliance Républicaine Démocratique“ in „Parti Républicain Démocratique“ im Dezember 1911 entsprang unter anderem auch dem Wunsch nach dezidierterer Abgrenzung; der kam auch im offiziellen Beschluß über die Unvereinbarkeit von Doppelmitgliedschaften seitens des PRD im Oktober 1912 erneut deutlich zum Ausdruck. ${ }^{50}$

Im Unterschied zu den Radikalsozialisten, die ihre Abgeordneten seit 1913 auf den Eintritt in eine gemeinsame Parlamentsfraktion verpflichteten und damit auch in der Chambre des Députés verstärkt eigenes Profil anstrebten ${ }^{51}$, bildete die „Alliance" nie eine einheitliche parlamentarische Gruppe. Fraktionszwang und obligatorische Unterordnung unter Entscheidungen der Parteileitung blieben in ihren Reihen ausgesprochen unpopulär und wurden im allgemeinen als Ausfluß falsch verstandener parlamentarischer Repräsentation oder als schädliche Abart des imperativen Mandats verworfen. ${ }^{52}$ Die für den Parteibildungprozeß in Deutschland im 19. Jahrhundert so entscheidende Verknüpfung außerparlamentarischer (Vereins)organisationen mit den parlamentarischen Fraktionen gelang im Bereich der rechten Mitte Frankreichs noch über die gesamte Zwischenkriegszeit hinweg nicht. ${ }^{53}$

Einen gewissen Ersatz für die fehlende organisatorische Basis boten der Partei ihre guten Beziehungen zu Handelskammern und wirtschaftlichen Interessengruppen. Insbesondere wurde die Verbindung zum „Comité républicain de Commerce, de l'Industrie et de l'Agriculture" von großer Bedeutung für den politischen Einfluß der Partei und ihre Verankerung innerhalb der sie tragenden Klientel. Diese nach ihrem Gründer auch „Comité Mascuraud“ genannte, auf nationaler Ebene organisierte und arbeitende Vereinigung hatte es sich seit 1898 zur Aufgabe gemacht, die Interessen von Handel und Industrie zu bündeln und politisch unter anderem durch die finanzielle Unterstützung vielversprechender Kandidaten zur Geltung zu bringen. Stand sie zunächst dem Parti Radical nahe, so wirkte sie nach dem Ersten Weltkrieg in erster Linie als Wahlhilfsorganisation der „Alliance“, von deren Unterstützung nicht zuletzt Paul Reynaud profitierte. ${ }^{54}$ Die politische Rolle, die die „Alliance“ spielte, - und die noch weit davon entfernt ist, hinreichend geklärt zu sein -, resultierte in erster Linie aus den oft bedeutenden Positionen, die ihre Mitglieder in den Regierungen der Dritten Republik einnahmen. Ohne genügendes parlamentarisches Potential, um aus eigener Kraft zu

50 Sanson, Centre et gauche, S. 507-509. Immerhin standen von den 1902 gewählten Abgeordneten der „Alliance“ knapp die Hälfte dem Parti Radical nahe oder waren dort Mitglied. Im Jahr 1906 waren gar 51 der 99 gewählten und in den Führungsgremien der „Alliance“ sitzenden Parlamentarier im Umfeld der Radikalsozialisten anzusiedeln (Ebenda, S. 499).

Im folgenden wird der Einfachheit halber die Bezeichnung „Alliance“ beibehalten, der gegenüber sich der neue Parteiname nicht durchsetzen konnte und zu der man folgerichtig ab 1926 in der Variante „Alliance démocratique“ zurückkehrte (Sanson, ARD ou AD), S. 50.

51 Berstein, Parti Radical I, S. 75.

s2 Wileman, L'Alliance, S. 18, Anm. 20; Albertini, Parteiorganisation, S. 584; Audigier, L'Alliance démocratique.

53 Dieter Langewiesche, Die Anfänge der deutschen Parteien. Partei, Fraktion und Verein in der Revolution von 1848/49, in: Geschichte und Gesellschaft 4 (1978), S. 324-361.

54 Im Jahr 1918 kam es im Zuge der Hochverratsanklage gegen den Parteivorsitzenden Caillaux zum Bruch zwischen „Comité Mascuraud“ und „Parti Radical“; vgl. hierzu Berstein, Parti Radical I, S. 96; allgemein zum Comité: Albertini, Parteiorganisation, S. 584 f. Zu den Verbindungen Reynauds und Mascurauds vgl. Kapitel VI dieser Arbeit. 
regieren, doch zeitweise stark genug, um entscheidend zum Sturz unerwünschter linksstehender Koalitionen beizutragen, konnte die Partei ihre Stellung in der Chambre des Députés zwischen 1902 und 1910 auf etwa 120 Abgeordnete ausbauen, bevor sie kurz vor dem Ersten Weltkrieg eine Schwächung ihrer parlamentarischen Position hinnehmen mußte. Genaue Zahlenangaben zur personellen Stärke der Gruppierung in der Kammer bleiben allerdings aufgrund der fortbestehenden Doppelmitgliedschaften und der geringen Neigung der Parlamentarier, die ihr nahestanden, sich zu ihrer Partei zu bekennen, auch für die Zeit nach dem Ersten Weltkrieg kaum möglich. ${ }^{55}$

Die ursprüngliche programmatische Nähe zum Parti Radical resultierte nicht zuletzt aus der Unbestimmtheit der frühen theoretischen Entwürfe beider Parteien: Man hatte sich ja gleichermaßen die Durchsetzung und Sicherung der laizistischen Republik, die Verteidigung eines gemäßigten Nationalismus und das Eintreten für einen weit gefaßten sozialen Fortschritt auf die Fahnen geschrieben. ${ }^{56}$ Erst im Verlauf der politischen Auseinandersetzungen der frühen Jahre ihres Bestehens stellte sich eine gewisse Ausdifferenzierung der jeweiligen Ziele insbesondere auf den Gebieten der Sozial- und Wirtschafts-, schließlich auch der Verteidigungspolitik ein. Es zeigte sich insbesondere die Skepsis der „Alliance“ gegenüber Ansätzen zur Ausbildung des modernen Interventionsstaates: Einer intensivierten staatlichen Sozialgesetzgebung mißtraute man ebenso wie dem im Parti Radical sehr populären „solidarisme“ Léon Bourgeois’. Auf wirtschaftlichem Gebiet gab man sich überzeugt antikollektivistisch, wandte sich gegen jedes Staatsmonopol und die Einführung der Einkommensteuer, die seit Jahrhundertanfang zum Standardprogramm der weitaus „interventionsfreudigeren“ Radicaux gehörte. ${ }^{57}$

In dem Maße, in dem die Notwendigkeit zur Verteidigung der republikanischen Errungenschaften nach dem Ende der Regierung Waldeck-Rousseau abnahm, schwand auch die Bereitschaft in der "Alliance“, jenen koalitionspolitischen Kompromiß aufrechtzuerhalten, der die eigene Gründungsphase geprägt hatte. Innerhalb des zentristischen Glaubensbekenntnisses der "Alliance“ mußte die antikollektivistische Komponente in dem Maße an Gewicht gewinnen, in dem das übergeordnete republikanische Ideal nicht mehr die Zurückstellung der Vorbehalte gegenüber den Sozialisten und all jenen Gruppen zu gebieten schien, die bereit waren, mit der extremen Linken zusammenzuarbeiten. So blieb die aktive Mitarbeit der „Alliance“ im „Bloc des Gauches“, jener durch Waldeck-Rousseau begründeten parlamentarischen Mehrheit, die von den Sozialisten bis zu den "républicains modérés" reichte und zwischen 1899 und 1909 eine ungewöhnlich lange Abfolge relativ stabiler Regierungen garantierte ${ }^{58}$, nur von begrenzter Dauer. War man noch anläßlich der Parlamentswahlen von 1906 bereit, eigene Kandidaten im zweiten Wahlgang zugunsten aussichtsreicherer radikalsozialisti-

55 Die Zahlenangaben beruhen auf den Schätzungen von Sanson, Centre et Gauche, S. 499 und 508. Sie sind aus den genannten Gründen mit Vorbehalt zu betrachten.

56 Sanson, Centre et Gauche, S. 498.

57 Ebenda, S. 499; Krumeich, Liberalismus, S. $361 \mathrm{f}$.

58 Zu Entstehung, Geschichte und Auflösung des „Bloc des Gauches“ vgl. Jean-Marie Mayeur, La vie politique sous la Troisième République, Paris 1984, S. 175-215. 
scher oder sozialistischer Bewerber zurückzuziehen ${ }^{59}$, so ging man in der Folge sehr bald von der bisherigen Mitte-Links-Taktik zu einer dezidierten Abgrenzungspolitik über. Mit der - letztlich gescheiterten - Lancierung eines zentristischen „Bloc républicain démocrate" 60 unter Ausschluß der Sozialisten und als Alternative zur bestehenden Mehrheit kündigte man im August 1907 de facto die Zusammenarbeit auf. Die damit eingeleitete Konsolidierung der „Alliance“ im Bereich der rechten Mitte ging einher mit weiterer personeller Entflechtung und politischer Entfremdung zwischen den beiden zentristischen Gruppen, vor allem nach der entschiedenen Weigerung der Radicaux, von Wahlbündnissen mit der sozialistischen Linken Abstand zu nehmen. Insbesondere in der Diskussion um die Einführung des dreijährigen Wehrdienstes und die Finanzierung der damit verbundenen neuen Rüstungsanstrengungen nahm die „Alliance“ eine überaus nationalistische, von sozialkonservativen Tendenzen geprägte Position ein. Sie stand im Gegensatz zur sachlicheren Haltung der eigenen Parlamentsmehrheit und veranlaßte selbst prinzipiell im gleichen Sinne optierende, antiradikale Gruppierungen dazu, auf Distanz zu gehen. ${ }^{61}$ Am Vorabend des Ersten Weltkrieges standen die beiden wichtigsten Gruppierungen des französischen Liberalismus in konkurrierenden Lagern. Nach dem Beitritt der „Alliance“ zur „Fédération des Gauches“ Briands, die als „parteiähnliches Gegengewicht zur radikalen Partei“62 konzipiert war, war das Bemühen zum erklärten Ziel der „Alliance“ avanciert, der „coalition d'extrême gauche réunissant radicaux-socialistes et collectivistes" 63 bei den Parlamentswahlen von 1914 eine Niederlage beizubringen - notfalls auch durch die Zusammenarbeit mit der gemäßigten Rechten. Der Wahlsieg der SFIO brachte der Gruppierung nicht nur die erste große Niederlage ihrer Geschichte bei, sondern machte deutlich, daß ihre Wählerschaft nicht gewillt war, diese Rechtsverschiebung der wichtigsten parlamentarischen Vertretung des nichtradikalen Liberalismus zu unterstützen. ${ }^{64}$

Paul Reynaud wählte von Beginn seiner Politikerlaufbahn an rechtsliberale oder allgemein „republikanische“ Etikettierungen, wenn es darum ging, in der Öffentlichkeit politisch Flagge zu zeigen. Während seiner ersten beiden Bewerbungen um ein Abgeordnetenmandat in Wahlkreisen des französischen Südostens trat er 1914 als Exponent der „Fédération des Gauches“, 1919 als Mitglied einer dem „Bloc national“ nahestehenden Liste auf. In beiden Fällen verknüpfte er das vage politische Signum mit stark individuell eingefärbter Programmatik. Die Positionen von liberalen politischen Gruppen, die auf nationaler Ebene, d.h. vorwiegend in Paris agierten, spiegelten sich darin nur tendenziell wider. Sein Fall illustriert

59 Auf diese Praxis der „désistements“ während der Wahlen von 1902 und 1906 weist Sanson, Centre et Gauche, S. 499 hin.

60 Zum „Bloc des républicains démocrates“ und zur Rechtswendung der „Alliance“: Sanson, Centre et Gauche, S. 505-510.

61 Zur Haltung der Alliance in dieser Frage und im Wahlkampf von 1914: Gerd Krumeich, Aufrüstung und Innenpolitik in Frankreich vor dem Ersten Weltkrieg. Die Einführung der dreijährigen Dienstpflicht 1913-1914 (Veröffentlichungen des Instituts für Europäische Geschichte Mainz, Band 96), Wiesbaden 1980, S. 170, 178f., 219-243.

62 Krumeich, Aufrüstung und Innenpolitik, S. 178.

63 "La Fédération des gauches", in: L'Alliance Républicaine Démocratique, 11. 1. 1914. Vgl. dazu: Sanson, Centre et Gauche, S. 510-512.

64 Krumeich, Aufrüstung und Innenpolitik, S. 229. 
deshalb einmal mehr die relative Eigengesetzlichkeit des regionalen politischen Lebens in Frankreich noch unmittelbar nach dem Ersten Weltkrieg: Nationale Wahlbündnisse konnten vor Ort eine eher unkonventionelle Umsetzung erfahren, und oft blieb genug Raum, um die programmatischen Festlegungen flexibel an die konkrete Wahlkampfsituation anzupassen. ${ }^{65}$

Vom Eintritt in eine der auf nationaler Ebene existierenden Parteien war sein schließlicher Wahlerfolg von 1919 nicht abhängig gewesen. Erst nach dem Antritt seines Parlamentsmandats entschied sich Reynaud mit einer gewissen, nicht weiter thematisierten Selbstverständlichkeit für die Zusammenarbeit mit dem 1911 aus der "Alliance“ hervorgegangenen "Parti Républicain Démocratique et Social“", nachdem er seine beiden ersten Wahlkämpfe noch ohne Parteianbindung bestritten hatte. Persönliche Herkunft und wirtschaftsbürgerliche Sozialisation, die frühen Kontakte zu den "modérés" seiner Heimatregion und die daraus resultierende Selbstwahrnehmung legten die Wahl nahe; ohne weiteres zwingend war sie im Rückblick betrachtet dennoch nicht. Der intellektuelle Republikanismus seiner frühen politischen Jahre machte Reynaud zeitweise empfänglich auch für Elemente linksliberaler Programmatik, ohne daß er deshalb freilich je geneigt gewesen wäre, seine politische Heimat etwa im Radikalsozialismus zu verorten. Die Disposition zum programmatischen Eklektizismus aber blieb ein Wesenselement seiner politischen Person, auch dann noch, als er sich zunehmend zur rechten Mitte hin orientierte. Gebändigt und gebündelt wurde diese Neigung zeit seines Lebens weniger durch das Bekenntnis zu einer Partei als durch jenes zur demokratischen Republik und zu ihrer Reform als Daueraufgabe.

Es bietet sich an, sein republikanisches „Glaubensbekenntnis“ zunächst näher zu bestimmen, um es dann in seiner praktischen Umsetzung während der Wahlkämpfe von 1914 und 1919 in den Blick zu nehmen. Da das Erlebnis des Ersten Weltkriegs für Reynaud mehr als für die Masse der Frontgeneration unmittelbare politische Konnotation hatte, wird es in dieser hinführenden Bestandsaufnahme ebenfalls zu berücksichtigen sein.

\section{Reynaud und das liberale Erbe: Republikanische Tradition und politische Praxis}

Was bedeutete es, so kann man in Anlehnung an Jean Touchard 66 fragen, Republikaner zu sein im Frankreich des frühen 20. Jahrhunderts? Zweifellos hat die Frage in den letzten Jahren vor dem Ersten Weltkrieg jene politische Brisanz verloren, die sie noch um 1900 besessen hatte. Der „Mut zur Einsamkeit“, der zumal in den konservativen Regionen Westfrankreichs noch im ausgehenden 19. Jahrhundert unabdingbar gewesen war, um sich als Anhänger der Republik zu exponieren, war im hauptstädtischen politischen Getriebe der Vorkriegsjahre sicherlich nicht mehr

65 Mit Blick auf die Radikalsozialisten kommt zum gleichen Ergebnis: Berstein, Parti Radical I, S. 119-128. Vgl. für die Periode zwischen 1871 und 1910 das Pionierwerk französischer Wahlsoziologie: André Siegfried, Tableau politique de la France de l'Ouest sous la Troisième République, Paris 1913.

66 Jean Touchard, La gauche en France depuis 1900, Paris 1981, S. 27-33, $69 \mathrm{ff}$. 
vonnöten. Die Verteidigung der Republik gegen ihre Gegner hatte sich innerhalb zweier Jahrzehnte von einem zentralen Thema des politischen und publizistischen Tageskampfes zu einem Gegenstand etablierter politischer Tradition und intellektueller Vergangenheitspflege gewandelt. Was vordem die wichtigste Scheidelinie zwischen Links und Rechts gewesen war, hatte sich zu einem politischen Modell mit hohem emotionalen Gehalt verdichtet, das von der sozialistischen Linken über die Radicaux bis zu den Modérés als verbindlich akzeptiert wurde.67 Im Laufe der ideologischen Verankerung der Republik seit 1871 angereichert und bewährt, verbanden sich in ihm historische Bezüge, philosophische Grundlegungen und verfassungspraktische Erfahrungen. Die Werte der Revolution, die siegreiche Auseinandersetzung mit den reaktionären Mächten von „Säbel und Weihwasserwedel" während der Affären um Dreyfus und Boulanger, schließlich der Verfassungskonflikt von 1877 bildeten wichtige Fixpunkte, die in der republikanischen Historiographie und im laizistischen Schulwesen mit großer Breitenwirkung überformt und tradiert wurden. ${ }^{68}$

Zweierlei ideologisch-politische Konstanten fanden mit dem „modèle républicain" Eingang in die politische Kultur Frankreichs. Zum einen wuchs der Republik ein "Gründungsmythos" zu, der sie im kollektiven Bewußtsein dauerhaft hinaushob über eine bloße Regierungsform. Daneben verband sich allmählich ein konkretes politisches Programm mit dem Epitheton „republikanisch“: „Défense républicaine", Antibonapartismus und Antiboulangismus, laizistische Staatsauffassung und der prinzipielle Vorrang der parlamentarischen Versammlung im Kräftespiel der Gewalten wurden in dieser Phase zu wesentlichen Determinanten des „republikanischen Konsensus“.69

Republikaner sein hieß also um 1911/13 zunächst einmal, den eigenen Standort gegenüber einem in wichtigen Bestandteilen noch jungen Traditionskorpus zu definieren. Es gehört zu den bis heute überdauernden Usancen französischer Politiker, zu solchem Zweck auf personale Leitbilder zurückzugreifen 70 ; Paul Reynaud machte hiervon keine Ausnahme. Sein Verhältnis zur politischen Tradition Frankreichs manifestierte sich zu Beginn nicht in theoretischen Programmschriften oder weltanschaulichen Abhandlungen und auch nicht in der Entscheidung für eine Partei. Selbst eher zum pragmatischen Vorgehen als zur breit angelegten Reflexion neigend, zeigte er sich in seinen ersten greifbaren traditionsbezogenen Äußerungen - der erwähnten Preisrede Waldeck-Rousseaus - stark beeinflußt

67 Ebenda, S. 32 (Zitat), 70.

$68 \mathrm{Vgl}$. Serge Berstein/Odile Rudelle, Avant-propos, in: Dies. (Hg.), Le modèle républicain, Paris 1992, S. 7-10. Zum Thema der republikanischen Synthese liegt mittlerweile eine reiche Literatur vor, als wichtigste Titel sind zu nennen: Claude Nicolet, L'idée républicaine en France (17891924). Essai d'histoire critique, Paris 1982; Ders., La République en France. Etat des lieux, Paris 1992; Ders./Michel Vovelle/Raymond Huard/Roger Martelli, La passion de la République. Un itinéraire français, Paris 1992. Insgesamt aufschlußreich auch die Beiträge des Sammelbandes: Paul Isoart/Christian Bidegaray (Hg.), Des Républiques françaises, Paris 1988.

69 Dazu im einzelnen: Michel Winock, Le mythe fondateur: l'affaire Dreyfus, in: Berstein/Rudelle, Modèle républicain, S. 131-145; Touchard, Gauche en France, S. 27-29.

70 In den sechziger Jahren durch die Presse befragt, reklamierte Valéry Giscard d'Estaing den Politiker Waldeck-Rousseau als politisches Vorbild, Georges Pompidou nannte Jean Jaurès; Michel Debré hingegen führte regelmäßig Jules Ferry ins Feld (zitiert nach Touchard, Gauche en France, S. 33). 
durch den liberalen Politiker, der wie er einen eher unkonventionellen politischen Ansatz pflegte.

\section{a) Reynauds Waldeck-Rousseau-Rezeption}

Die Würdigung Waldeck-Rousseaus, die Reynaud ursprünglich für einen berufsständischen Rahmen vorgesehen hatte, ging in ihrer schließlich veröffentlichten Fassung ${ }^{71}$ deutlich über das hinaus, was in den Preisreden der Pariser Anwaltskammer an Inhalt und Anspruch für gewöhnlich geboten wurde. ${ }^{22}$ Nicht die Laudatio des brillanten Juristen stand im Mittelpunkt der Darlegungen, sondern die Reminiszenz an den Politiker und Staatsmann, der im Frankreich der Vorkriegszeit wie wenige andere die siegreiche laizistische Republik und das politische Profil "gemäßigten" Republikanertums verkörperte. Eine Reminiszenz freilich, die keineswegs dokumentarischen Anspruch in den Vordergrund rückte. Zwar lag ihr durchaus intensives Quellen- und Literaturstudium, ergänzt durch die Befragung von Zeitzeugen, zugrunde. Die Grenzen des den Zeitgenossen vorliegenden historischen Wissens über den Politiker zu erweitern vermochte sie jedoch nicht.73 Die Studie reihte sich vielmehr bewußt ein in die früh nach dem Tode WaldeckRousseaus beginnende Auseinandersetzung mit dessen politischem Lebenswerk, in der sie nicht kritiklos, doch deutlich von Bewunderung geprägt Stellung bezog. Ein Akt des Republikschutzes in akuter Gefahrensituation war sie kaum, auch wenn sich Reynaud redlich mühte, den großen republiktragenden Stellungnahmen eines Poincaré oder Zola im Gestus nahezukommen. Er gab „seinen“ Waldeck-Rousseau und bot damit in erster Linie ein gerüttelt Maß an Selbstpräsentation. So ist es weniger der Untersuchungsgegenstand selbst, der das eigentliche Interesse der Darstellung ausmacht: Vielmehr erscheint hinter der skizzenhaften politischen Biographie der Schattenriß eines spezifischen Geschichts-, Politikund Reformverständnisses ihres Autors.

Im Mittelpunkt steht ein Dreistufenmodell französischer Geschichte seit 1870, dessen politische Wirkabsicht sich auf die Gegenwart richtet. Einer Phase hoffnungsvoller Reformansätze während der Ministerpräsidentschaft Gambettas 1881/82 folgte in Reynauds Wahrnehmung eine krisenhafte Periode der Instabilität, geprägt von außenpolitischen Niederlagen, innenpolitischen Skandalen und der Bedrohung der Republik durch rechtsextreme Strömungen. Erst das Eingreifen Waldeck-Rousseaus zwischen 1899 und 1902 habe eine erneute Konsolidierungsphase eingeleitet, in der über Reformen insbesondere im Bereich der Sozial-

71 Paul Reynaud, Waldeck-Rousseau, Paris 1913.

72 Vgl. dazu einen Querschnitt in: „Discours de rentrée des conférences. Avocats stagiaires 19111920“ (Archives de l'Ordre des Avocats à la Cour de Paris).

73 Zum Zeitpunkt der Abfassung der Studie Reynauds lag als erste und bis dahin einzige quellenmäBig abgesicherte Darstellung die Arbeit von Henry Leyret vor, der als junger Journalist das Vertrauen Waldeck-Rousseaus gewonnen hatte und nach dessen Tod 1904 durch die Witwe mit der Abfassung einer Biographie betraut worden war. Auf der Grundlage des Nachlasses des Politikers, zu dem er freien Zugang hatte, veröffentlichte er 1908 einen bis ins Jahr 1889 reichenden ersten Teilband des geplanten Werks: Henry Leyret, Waldeck-Rousseau et la Troisième République (1869-1889), Paris 1908. Nachdem er ohne Einwilligung der Familie unbekannte Stücke des Nachlasses dem konservativen Matin zugespielt hatte, war an eine Fortsetzung des Werks nicht zu denken (Pierre Sorlin, Waldeck-Rousseau, Paris 1966, S. 529 f. und 549). 
ordnung die Grundlagen des modernen Frankreich gelegt worden seien. Diese neugewonnene Synthese der gesellschaftlichen Antagonismen durch eine Politik der Restauration der „republikanischen Idee“ erscheint Reynaud zum Zeitpunkt der Abfassung der Studie allerdings bereits wieder stark gefährdet.

$\mathrm{Daß}$ es sich hierbei um eine äußerst selektive Darstellung handelt, liegt auf der Hand. Aufschlußreich aber sind neben Reynauds Stellungnahmen zum konkreten politischen Handeln Waldeck-Rousseaus in erster Linie die Ursachenanalysen von Krise und Wiederaufschwung. Bei Reynaud erscheint der Sturz Gambettas im Januar 1882 durch eine reformfeindliche Koalition als Symptom für eine gravierende „Krise des Parlamentarismus“, ausgelöst durch die Niederlage des „republikanischen Ideals" gegenüber eigensüchtigem Wahlkalkül und schädlichen Partikularinteressen. ${ }^{74}$ In scharfer Gesellschafts- und Parlamentarismuskritik werden die tieferen Wurzeln auf zweierlei Ebenen verortet: in der Dekadenz des politischen Personals, dessen Eigennützigkeit durch Mängel des Verfassungsrechts wie beispielsweise die Persönlichkeitswahl gefördert werde, einerseits; in der indifferenten Haltung der Öffentlichkeit, die ohne Protest zugesehen habe, als „der Tiger den Dompteur tötete“, andererseits. ${ }^{75}$ Reynaud verlagert damit die stärker personenzentrierte und tagespolitisch orientierte Argumentation seiner Vorlage, der Studie Leyrets, auf eine grundsätzliche Ebene: Er diagnostiziert ein zerstörerisches Klima der Gleichgültigkeit gegenüber der republikanischen Tradition, das er gleichermaßen verantwortlich macht für den Sturz des „patriotischen“ Reformers wie letztlich auch für das Aufkommen reaktionärer Strömungen und deren Angriffe auf die Republik im Verlauf der Dreyfus-Affäre. ${ }^{76}$ Das Bild, das Reynaud von der Widerstandskraft der republikanischen Öffentlichkeit Frankreichs am Vorabend jener Bewährungsprobe entwirft, ist vernichtend. Pessimismus, Zynismus und politische Gewalttätigkeit dominierten neben Klassengegensätzen, die durch politische Parteiungen eher verstärkt denn überbrückt worden seien; sie hätten Politik und Gesellschaft unfähig zur Lösung jener latenten Antagonismen gemacht, die sich um die Ideenkreise von "Révolution“ und "contre-Révolution“ gruppierten. Impulse zur Reform kamen demnach weder aus dem „peuple“, der ohne „ambition collective“ lediglich nach persönlichem Wohlergehen strebte, noch aus den adeligen und bürgerlichen Führungsschichten, die sich angesichts der Mißstände vom öffentlichen Leben abgewandt oder auf eine Art „nihilisme bourgeois " zurückgezogen hätten.7"

Zur Beschreibung der komplexen historischen Realität wenig geeignet, zielte Reynauds Analyse im Stile einer rückwärtsgewandten Utopie auf die kritische Bestandsaufnahme der aktuellen Situation. Kaum verdeckt griff der junge Anwalt daher die Topoi einer Reformdiskussion auf, die etwa seit der Jahrhundertwende die politische Öffentlichkeit Frankreichs in all ihren Schattierungen erfaßt hatte.

Krisenbewußtsein und Reformstreben nährten sich unter anderem aus der Er-

74 Reynaud, Waldeck-Rousseau, S. 79.

75 Ebenda, S. 77-81.

76 Ebenda, S. 80. In der Darstellung Leyrets erscheint der Sturz Gambettas vorwiegend durch dic Vorbehalte des Parlaments gegenüber vermeintlichen bonapartistischen Tendenzen des Regierungschefs begründet (Leyret, Waldeck-Rousseau, S. 203-208).

7 Reynaud, Waldeck-Rousseau, S. 166-170. 
fahrung einer neuen Periode politischer Turbulenzen, die die Phase relativer Stabilität zwischen der Regierungsübernahme Waldeck-Rousseaus und dem Sturz der Regierung Clemenceau im Jahre 1909 abgelöst hatte. Die rasche Abfolge teils äußerst kurzlebiger Regierungen - in den verbleibenden fünf Jahren bis zum Ersten Weltkrieg nahmen elf Kabinette die Regierungsgeschäfte wahr - bildete den objektiv erfahrbaren Hintergrund für das verbreitete und oftmals eher diffuse Ungenügen an einer allgemeinen "malaise" des politischen Lebens. Wachsende Zweifel an der Effizienz einer „Honoratiorendemokratie“ verbanden sich darin mit Thesen von der Dekadenz des politischen Personals und mit der Kritik an Defiziten sozialer Teilhabe. Charakteristisch für diese Vertrauenskrise des herrschenden politischen Systems und des Parlamentarismus im besonderen war es, daß sie sich parallel zur Stabilisierung der Republik angebahnt hatte. Auch wenn die parlamentarische Demokratie spätestens nach den Verwerfungen der Dreyfus-Affäre gefestigt und nicht mehr unmittelbar gefährdet war, hatte sie weiterhin wie überhaupt seit der Republikgründung mit antiparlamentarischem Denken zu konkurrieren. Vorzufinden war es sowohl auf seiten der extremen Linken wie auf der Rechten, und eine ganze Reihe von politischen Skandalen hatte dazu beigetragen, $\mathrm{da}$ es Rückhalt auch in der öffentlichen Meinung fand. Um die Jahrhundertwende war ein neuformierter rechter Nationalismus als Erbe boulangistischer und bonapartistischer Strömungen neben der syndikalistischen Bewegung zum lautstärksten Träger geworden. Im Neo-Royalismus der „Action Française“ um Charles Maurras bündelten sich dann antirepublikanische, antiparlamentarische und antidemokratische rechte Tendenzen in einer neuen Doktrin mit reformistischem Anspruch, wenngleich schwer bestimmbarem Einfluß.78

Teilweise in Reaktion darauf manifestierte sich eine demokratische, republikanische Erneuerungsbewegung. Ihre Krisenlösungskonzepte umfaßten ein weites Spektrum, ausgehend von Plänen für eine Verstärkung plebiszitärer Elemente in der Verfassungsstruktur bis hin zu allgemeinen Appellen zur Restauration des Geists der Republikgründer. Daneben standen Überlegungen, die aus der empirisch fundierten Einsicht der Sozial- und Staatswissenschaften in die fortschreitende Verflechtung von Staat und Gesellschaft theoretisch untermauert werden konnten. Begünstigt durch die Rehabilitierung der in der nachrevolutionären Staatslehre als reaktionär stigmatisierten "corps intermédiaires" wurden in Politik und Publizistik verschiedenster Couleur Reformpläne entwickelt, die der veränderten gesellschaftlichen Situation über die parteipolitisch oder korporativ orientierte Organisation des Willensbildungsprozesses Rechnung zu tragen versuchten. Die Forderung nach Einführung der Verhältniswahl geriet zu einem Schwerpunkt dieser durchaus vielgestaltigen und heterogenen Erneuerungsbewegung, deren Anhängerschaft aus allen im Parlament vertretenen politischen Richtungen kam. ${ }^{79}$

78 Mayeur, Troisième République, S. 215; Madeleine Rebérioux, La République radicale? 1898-1914 (Nouvelle histoire de la France contemporaine 11), Paris 1975, S. 137. Zur Entwicklung der Rechten: René Rémond, Les Droites en France, Paris 1982, S. 148-180; Dominique Borne, Antiparlementarisme, in: Sirinelli (Hg.), La vie politique française, S. 36-38; Eugen Weber, L'Action française, Paris 1985.

79 Bislang existiert keine zusammenfassende Aufarbeitung dieser komplexen und vielgesichtigen Reformbewegung, die die öffentliche Diskussion im Frankreich der Vorkriegszeit stark beeinflußte. 
Darüber hinaus trat die soziale Frage wieder in den Vordergrund, nachdem sie seit den neunziger Jahren durch die Problemkreise „Défense républicaine“ und "laïcité" weitgehend aus der öffentlichen Diskussion verdrängt worden war. Die wachsende Unzufriedenheit der Arbeiterschichten, ab 1904 in einer Welle von Streiks konkretisiert, verwies ebenso wie das Erstarken des revolutionären Syndikalismus auf dringenden sozialpolitischen Handlungsbedarf. Die bürgerlichen Regierungen der Vorkriegszeit stellten sich diesem zwar, kamen ihm jedoch nur in einem Maße nach, das weit unter den Forderungen der Sozialisten lag. ${ }^{.0}$ Allerdings hatte sich seit dem letzten Jahrzehnt des 19. Jahrhunderts auch auf diesem Feld eine Vielzahl von Lösungsmodellen manifestiert. Das Ideenspektrum reichte von paternalistisch geprägten Genossenschaftsmodellen über Léon Bourgeois' Theorie des „solidarisme“ bis zu Plänen für eine „économie sociale“. Ein zentrales Prinzip, das diesen bürgerlichen Reformplänen zugrundelag, strahlte auch auf führende republikanische Politiker aus, unter anderem auf Waldeck-Rousseau: die wirtschaftliche und kulturelle Integration der Arbeiterschaft und ihre Immunisierung gegen sozialistische Ideen durch die Heranbildung einer Solidarbeziehung zwischen Kapital und Arbeit. 81

Reynauds Initiative stand in diesem weitgespannten und von zukunftsweisenden Ansätzen gekennzeichneten Diskussionsrahmen. Einem einzelnen der neuen Theorieansätze ließ sie sich indes keineswegs eindeutig zuordnen. Staatsreform, Laizität und soziale Frage erörterte er vielmehr im Zusammenhang eines allgemein gehaltenen Republikanismus, Reformansätze nahm er durch das politische Werk Waldeck-Rousseaus hindurch auf. Zwei Ideenschichten unterschiedlichen Abstraktionsgrades lassen sich hierbei voneinander trennen.

$\mathrm{Da}$ ist zunächst der Gedanke der notwendigen Einheit aller republiktragenden Kräfte in Zeiten der Krise. Mehr als ein bloßer rhetorischer Topos, rührte Reynauds Appell auf Neubelebung des Erbes Waldeck-Rousseaus an eine Tiefenschicht republikanischer Kultur. Diese in der konkreten historischen Situation zu aktivieren hieß, systemsprengende autoritäre, nationalistische oder antiparlamen-

$\mathrm{Zu}$ ihren Hintergründen und Inhalten mit besonderem Blick auf den Aspekt der Wahlreform: Werner Scherer, Verhältniswahl und Reform der politischen Ordnung. Die Auseinandersetzung um den Proporz in Frankreich bis zur Wahlreform von 1919, Diss. Heidelberg 1982; zur Haltung der Parteien und zu deren durchaus nicht immer uneigennützigen Motiven: Ebenda, S. 413-544. Den Reformaspekt der Stärkung der präsidialen Stellung erörtert u.a. auch für die Zeit vor 1914: Hugues Taÿ, Le régime présidentiel et la France. Etude d'histoire des idées juridiques et politiques, Paris 1967, S. 61-64; allgemein auch: Rebérioux, République radicale?, S. 138 f.; Mayeur, Troisième République, S. $219 \mathrm{f}$.

80 Georges Bonnefous, Histoire politique de la Troisième République. Band I: L'avant-guerre (19061914), Paris ${ }^{2} 1965$, passim; Wilfried Loth, Geschichte Frankreichs im 20. Jahrhundert, Stuttgart u. a. 1987, S. 11-19, hier: S. 18.

81 Elwitt, Third Republic Defended; speziell zu Waldeck-Rousseau: S. 202, 197, 99 f.; Stone, Search for Social Peace, passim.

Stufenweise hat die Forschung die lange vorherrschende Auffassung vom sozialpolitischen Desinteresse der französischen "modérés" eingeschränkt und differenziert. Konnte Pierre Sorlin in seiner Studie über Waldeck-Rousseau die These zunächst anhand einer prägenden Einzelpersönlichkeit relativieren, wurden in Studien allgemeinerer Art (François Ewald, La politique sociale des opportunistes, 1879-1885, in: Serge Berstein/Odile Rudelle (Hg.), Le modèle républicain, Paris 1992, S. 173-187, bzw. Serge Berstein, La politique sociale des Républicains, in: ebenda, S. 189208) oder in den empirisch fundierten Untersuchungen von Elwitt und Stone Belege für ein umfassenderes sozialpolitisches Reformpotential in den Reihen der Liberalen geliefert. 
tarische Erneuerungsvorstellungen zurückzuweisen. Spektakulär war das nicht, behielt aber seine Aussagekraft, wenn es sich wie hier mit der Bereitschaft verband, demonstrativ auf die Entwicklungsfähigkeit des Bewährten zu setzen. Jene wird sichtbar, sobald man eine zweite Schicht verfassungs- und gesellschaftstheoretischer Vorstellungen zu isolieren versucht, die auf Reynauds republikanischem Glaubensbekenntnis aufbauten und es zugleich präzisierten. So ließ er keinen Zweifel daran, daß nach seinem Verständnis von parlamentarischer Demokratie das Wechselspiel zwischen Exekutive und Legislative nicht zu Ungunsten ersterer ausschlagen durfte. Reynaud setzte sich damit ab von den Anhängern strikter parlamentarischer Präponderanz, zeigte sich beeinflußt von parlamentarismuskritischen Tendenzen seiner Zeit und vermied doch den letzten, systemtranszendierenden gedanklichen Schritt. Abhilfe gegen die fortwährende Kabinettsinstabilität und die Praxis rein destruktiver Kammermehrheiten tat auch in seinen Augen not, und die Stärkung der Exekutive kam dabei als Reformstrategie durchaus in Frage. Das Betreten von Tabuzonen jenseits des engeren republikanischen Referenzsystems vermied er freilich sorgfältig. Dazu gehörten insbesondere Pläne zur Stärkung der präsidialen Stellung über die Ausweitung des Wählergremiums, wie sie in der nationalistischen „Ligue des Patriotes" von Paul Déroulède oder der gemäBigteren "Action libérale populaire" um Charles Benoist ohne umfassendere Resonanz formuliert worden waren. ${ }^{82} \mathrm{Als}$ starkes Gegengewicht gegen die Übermacht des "gouvernement d'assemblée" favorisierte Reynaud den mit Autorität und Führungskraft begabten Regierungschef: „Dans une démocratie, il faut que le chef du gouvernement soit un conducteur d'hommes. Le premier, Waldeck-Rousseau le fut. Il comprit qu'un chef de gouvernement n'est vraiment un chef qu'à la condition de prendre sur l'opinion publique un point d'appui contre les intrigues du Parlement“. 83 Das Idealbild, das Reynaud konstruierte, versah den „Président du Conseil“" zusätzlich mit jenen Attributen, die dem Staatspräsidentenamt nach dem faktischen Entzug seiner im engeren Sinne politischen Prärogativen seit 1877 noch geblieben waren: So stilisierte er Waldeck-Rousseau zum beispielhaften überparteilichen Meinungsbildner und Integrationsfaktor. ${ }^{84}$

Im Ansatz ähnelte diese Lösung dem Konzept, das Léon Blum wenige Jahre später in seinen „Lettres sur la Réforme gouvernementale" vortrug: Der Ministerpräsident sollte demzufolge als wahrer "Chef" in „autokratischer" Manier und mit einem institutionalisierten Hilfsapparat ausgestattet die Leitung der Regierungsgeschäfte in Händen halten. ${ }^{85}$ Systematischer und konsequenter als die Vorstellungen Reynauds präsentierten sich diese Überlegungen allerdings in zweierlei

82 Taÿ, Régime présidentiel, S. 43-64; Mayeur, Troisième République, S. 219; unsystematisch: Jochen Hoock, Le problème de la Réforme de l'Etat en France, 1880-1935, Thèse Paris 1970, S. 64 ff.

83 Reynaud, Waldeck-Rousseau, S. 179.

84 "C'est lui [Waldeck-Rousseau, A.d.V.] cependant qui, en ces temps troublés, fit apparaître au Parlement et au pays la grande figure de la loi. Il gouverna non comme un partisan qui dispose de la force publique mais comme l'exécuteur des lois. Il rétablit le silence dans les assemblées et sur toutes les grandes questions, il enseigna au pays ce qu'il devait penser" (Reynaud, Waldeck-Rousseau, S. 178).

85 Léon Blum, Lettres sur la Réforme gouvernementale, Paris 1918, in: L'Oeuvre de Léon Blum. Band 3/1, 1914-1928, Paris 1972, S. 507-574; dazu die Interpretation bei: Gilbert Ziebura, Léon Blum. Theorie und Praxis einer sozialistischen Politik. Band I: 1872 bis 1934, Berlin 1963, S. 148160, bes. S. 154-156; Jean Lacouture, Léon Blum, Paris 1977, S. 141-144. 
Hinsicht. Sie implizierten zum einen die bis dahin nicht bestehende rechtliche und praktische Verankerung des Ministerpräsidentenamts im politischen System Frankreichs - ein Schritt zur Stabilisierung der Exekutive, der de facto erst 1935 erfolgte. Zum andern gruppierten sich die Reformideen Blums um eine Kernforderung, die zweifellos erfüllt sein mußte, um die so oft vermißte Handlungseinheit zwischen Kammermehrheit und Regierung herzustellen: die Herausbildung wohlorganisierter, disziplinierter Parteien. Sicherlich war auch Blum realistisch genug, nicht auf unmittelbare Umsetzung zu hoffen, und um 1918 konnte von einem organisatorischen Vorsprung der sozialistischen Partei gegenüber ihren bürgerlichen Konkurrenten erst in Ansätzen die Rede sein. Eine möglichst geeinte, schlagkräftige Partei blieb aber im politischen Handeln Blums ein kontinuierlich verfolgtes Ideal, auch wenn der Weg dorthin von vielen Rückschlägen begleitet sein mochte. ${ }^{86}$

Historiographisch faßbaren Stellenwert erlangte der Parteigedanke als Reformidee im politischen Denken Reynauds erst nach 1919. Auch dann noch wahrte er ihm gegenüber ein ambivalentes, widersprüchliches Verhältnis, das weniger auf prinzipieller intellektueller Negation beruhte als auf der praktischen Unvereinbarkeit mit der politischen Kultur, der er sich zeit seines Lebens zugehörig fühlte. Bei allem Reformstreben blieb Reynaud bis in die letzten Wochen seiner politischen Tätigkeit prononcierter Verfechter des deliberativen Parlamentarismus und der politischen Konnotationen, die ihm anhafteten: die Verkörperung der Nation in der souveränen Volksvertretung, die Ablehnung des imperativen Mandats und die Skepsis gegenüber intermedïren Instanzen zwischen Nation und „député“. Der notwendigen Bündelung der politischen Kräfte in der Kammer und im Land als einem Element zur Modernisierung der französischen Demokratie verschloß er sich schon vor 1914 keineswegs. Trotz mancher Reformpläne vor allem nach 1926 aber förderte und nutzte er im Laufe seiner politischen Karriere in parteiorganisatorischer Hinsicht eher Vor- oder Teilformen wie Fraktion, Wahlkomitee und quasi- bzw. „parapolitische“ Vereinigungen, die die Meinungs- und Handlungsfreiheit ihrer Mitglieder nur in Ansätzen beschnitten. ${ }^{87}$ Daneben rückte er - wie zu zeigen sein wird - vorwiegend parteiunabbängige Reformmechanismen in den Vordergrund, die technischer, ideeller und personengebundener Art waren, so etwa die Revision des Kammerreglements oder später des parlamentarischen Auflösungsrechts. ${ }^{88}$ Seine Waldeck-Laudatio belegt zwei frühe Varianten: den konzeptionellen Rückgriff auf die starke, überparteiliche und einheitstiftende Rettergestalt in Krisenzeiten, zum einen. Als kollektiver politischer Reflex zur Umgehung von Systemschwächen kannte dieses Modell im Frankreich des 20. Jahrhunderts, von Poincaré bis de Gaulle, eine erstaunliche Karriere, die nach wie vor der systematischen Erforschung harrt.

86 Ziebura, Léon Blum, S. 154 und $215 \mathrm{ff}$. Speziell für die Periode nach der Spaltung von Tours: Tony Judt, La reconstruction du parti socialiste, 1921-1926, Paris 1976, S. 55-68.

$87 \mathrm{Zu}$ den Organisationsformen der politischen Mitte und der Rechten in Frankreich im Überblick: Gilles Le Béguec, Le parti, in: Jean-François Sirinelli (Hg.), Histoire des Droites en France. Band 2: Cultures, Paris 1992, S. 13-59; Serge Berstein, Les partis, in: René Rémond (Hg.), Pour une histoire politique, Paris 1988, S. 49-85; Jean-Pierre Rioux, L'association en politique, ebenda, S. 87-120.

88 Vgl. dazu Kapitel IX.1.b). 
Zum andern zeigte sich Reynaud einer Änderung des Wahlrechts aufgeschlossen gegenüber, wie sie Waldeck-Rousseau in Form des „scrutin élargi“ zur Eindämmung lokaler Einflüsse auf die Deputierten unterstützt hatte. Reynaud brauchte sich dabei gar nicht als Befürworter der Verhältniswahl zu exponieren: allein der Name Waldecks stand bereits für die Einführung des Listenwahlsystems anstelle der geltenden Mehrheitswahl auf Arrondissementsebene. Wie sein Vorbild erwartete er davon zu allererst die Konstituierung einer auf Sachfragen hin orientierten, funktionsfähigen Opposition und das Ende der Praxis rein destruktiver Mehrheiten, jener „Krankheit“, die, so Reynaud, den französischen Parlamentarismus neben der Schwäche der politischen Mitte zeichne. Das Zwischenglied funktionierender Parteien war zur Erlangung dieses Effekts im Waldeck/ Reynaud'schen Verständnis nicht nötig: Es genügte bereits, daß voraussichtlich ein neuer Abgeordnetentypus favorisiert würde, der weniger die Mikrointeressen seiner Klientel als das imaginäre allgemeine Wohl im Auge hätte. ${ }^{89}$ - Ein Politikertypus, dem sich Reynaud zweifellos selbst zurechnete.

Nicht die konsequent angelegte Parteiendemokratie also schwebte Reynaud vor, sondern eine revidierte Honoratiorendemokratie, deren Volksvertreter in klassisch deliberativer Manier über das allgemeine Beste zu befinden hatten. Weitestgehend unbehelligt von Zwängen verbindlicher Doktrinen und diszipliniert eher aus frei verantworteter eigener Entscheidung denn über sanften prozeduralen Druck. Es handelte sich dabei um ein in mehrfacher Hinsicht an republikanisch-liberalen Traditionen orientiertes Modell, das weder die Verfassungsgesetze von 1875 antastete noch den seit 1877 verfassungspraktisch gesicherten „Sieg des parlamentarischen Prinzips “90 über das präsidiale Amt in Frage stellte. Reynaud verlor im Laufe seiner parlamentarischen Arbeit einige Illusionen über die Reformierbarkeit des politischen Systems seines Landes, an den hier formulierten Präferenzen aber hielt er dauerhaft fest.

In solchem Rahmen kam es eher einer republikanischen Pflichtübung gleich, wenn er die religionspolitischen Maßnahmen Waldeck-Rousseaus, insbesondere sein Vorgehen gegen die Ordensgemeinschaften im Zusammenhang des Gesetzesprojekts vom November 1899, befürwortete und beredt verteidigte. Die Rechtfertigung gesetzlicher Maßnahmen zum Verbot mißliebiger Kongregationen, die er bot, entfaltete das argumentative Standardprogramm, das bis in die Fünfte Republik zur Begründung laizistischer französischer Staatlichkeit herangezogen wurde. Es finden sich zum einen die historisch-politisch-rechtlichen Gründe, so insbesondere der Gedanke, die mißbräuchliche Einmischung einiger, vom Geist der Gegenrevolution beseelter Kongregationen in die Politik abzuwenden, dem unmäßigen Anwachsen des Besitzes der „toten Hand“ zu steuern und nicht zuletzt das ungeregelte Verhältnis zwischen Staat und "clergé régulier" auf eine gesetzliche Basis zu stellen. Zum andern aber führte Reynaud den entscheidenden staatsphilosophischen Aspekt ins Feld: die seit der Revolution prinzipiell vorgegebene säkulare Grundlegung der Republik. Deren Nichtanerkennung bringe

89 Reynaud, Waldeck-Rousseau, S. 74-76, 105 f. Zu den Ideen Waldecks hierzu: Sorlin, WaldeckRousseau, S. 225-229; zur Reformdiskussion allgemein: Mayeur, Troisième République, S. 217 220.

90 Klaus von Beyme, Die parlamentarischen Regierungssysteme in Europa, München 21973, S. 226. 
jene Kreise der katholischen Kirche, die sich nicht der Aufforderung Leos XIII. zum „ralliement" fügen wollten, notwendigerweise in Gegensatz zu einem fundamentalen „Lebensgesetz“ des so begründeten Staatswesens: „[... ] si l'autorité n'est légitime qu'à la condition de descendre de Dieu par les échelons de la hierarchie de l'Eglise, il y a un antagonisme irréductible entre l'Eglise catholique et la société issue de la Révolution française". ${ }^{91}$ Spektakulär war dies weniger als entschieden staatstragend. Seitenhiebe dieser Art sicherten Reynaud in jedem Falle die dauerhafte Feindschaft der "Action Française“.

Auf dem Gebiet der Sozialpolitik entwickelte er in Anlehnung an WaldeckRousseau den entschiedensten Standpunkt. Reynaud bezog hier engagiert Stellung für das Gewerkschaftsgesetz von 1884, das für die Beurteilung Waldecks durch die Nachwelt schnell zentrale Bedeutung und im Verlaufe der sozialen Unruhen ab 1904 dann unerwartete Aktualität erhalten hatte. Lebhaft stilisierte er den Streit um die Legalisierung der „syndicats“ zur Auseinandersetzung zwischen "optimisme révolutionnaire qui croit que rien de mauvais ne peut sortir de la liberté" und "pessimisme chrétien sur la faiblesse de la nature humaine“, zwischen Orientierung am Wählerwillen und „despotisme éclairé". 92 Freilich war es nicht die Sicht des Gewerkschaftsaktivisten, die sich Reynaud zu eigen machte: Die gewerkschaftliche Organisation der Arbeiter verstand er mit Waldeck-Rousseau nicht als Mobilisierungs-, sondern als Kanalisierungsinstrument, als Mittel, die Masse der Lohnabhängigen an die demokratische Ordnung zu binden, letztlich als Auffangbecken zur Mäßigung extremistischer Tendenzen und zur reformerischen Umsetzung revolutionären Potentials: „Le mouvement syndical a mis fin aux bombes anarchistes" ${ }^{93}$ Klassisch liberales Denken bestimmte diese Interpretation, der nicht der Gedanke des unausweichlichen Antagonismus gesellschaftlicher Kräfte, sondern der Glaube an die Selbstregulation sozialer Konflikte zugrunde lag: Trotz aller eigensüchtigen Motive auf beiden Seiten werde sich die $\mathrm{Ge}$ werkschaftsbewegung letztlich nicht der höheren Logik der wirtschaftlichen Prozesse entziehen können, von denen sie selbst abhänge. ${ }^{94} \mathrm{Z}$ wischen den Interessen der Allgemeinheit und denjenigen der Arbeiterschicht lagen in dieser Sehweise keine grundsätzlichen und unüberbrückbaren Unterschiede; vielmehr entsprach

91 Reynaud, Waldeck-Rousseau, S. 196-226, hier: S. 209. Zur Aktion Waldeck-Rousseaus in diesem Zusammenhang: Sorlin, Waldeck-Rousseau, S. 423-460; Maurice Larkin, Church and State after the Dreyfus Affair. The Separation Issue in France, London 1974, S. 80-91; John McManners, Church and State in France, 1870-1914, London 1972, S. 118-128. Der verhältnismäßig geringe Anteil Waldeck-Rousseaus an der endgültigen, verschärften Fassung des Gesetzes vom 1.Juli 1901, den Sorlin herausarbeitet, war Reynaud noch nicht bekannt.

Als Beispiel einer modernen Rechtfertigung der Laizität der französischen Republik und allgemein zum Problem des Verhältnisses von „République et laïcité vgl. Nicolet, République en France, S. 100-121.

92 Ebenda, S. $96 \mathrm{f}$.

93 Ebenda, S. 98 f. (Zitat: S. 99).

94 „Il est vrai que le tempérament national est impressionnable et nerveux, que les grèves semblent apparaître aux ouvriers comme des épopées périodiques dans la vie morne de l'usine et que, poussés par la faim, ils se montrent parfois alors aussi peu respectueux de la loi que la fraction la plus avancée des partis d'opposition. Il est cependant dans la force des choses que ces mouvements soient limités comme les ressources mêmes de ceux contre qui ils sont dirigés. Les ouvriers pourront exiger une participation de plus en plus grande dans les bénéfices du patron, Etat ou particulier, et rendre ainsi les créateurs d'affaires plus timorés dans leurs entreprises, mais ils n'auront jamais intérêt à supprimer l'industrie dont ils vivent" (Reynaud, Waldeck-Rousseau, S. 100f.). 
es dem Interesse des Ganzen, eine so bedeutende gesellschaftliche Strömung zur Entfaltung kommen zu lassen: „[... ] lorsqu'un mouvement de cette importance est en voie de formation, le plus grand péril pour la société consiste à le mettre en antagonisme avec la loi".95 Den zunehmenden Wohlstand der Arbeiter wie auch ihrer Vertretungen verstand Reynaud als Korrektiv, um gleichsam auf „natürlichem" Wege die Anerkennung der bestehenden Sozialordnung durch die zu politischem Bewußtsein erwachten Arbeiterschichten voranzutreiben. ${ }^{96}$

Das Harmoniemodell, das Reynaud vortrug, hatte von Anbeginn der Diskussion um die Zulassung berufsständischer Vereinigungen den Standpunkt der bürgerlichen Befürworter geprägt, als es nach 1871 darum gegangen war, die faktische Duldung jener „syndicats“, die seit Niederschlagung der Kommune neu entstanden waren, durch eine klare rechtliche Regelung zu ersetzen. So figurierte die „Erziehungs-" und Integrationsfunktion der Gewerkschaften in der Begründung des ersten Gesetzesprojekts zur Einführung der „liberté syndicale“ im Jahre 1876. In der Folge wurde sie gleichermaßen Teil des frühen „Sozialprogramms“ der Radikalen und der linken Mitte um Gambetta wie des Selbstverständnisses des minoritären gemäßigten Flügels der entstehenden Gewerkschaftsbewegung.97 Durch Waldeck-Rousseau aufgegriffen, bildete die Konzeption des „syndicalisme coopé-

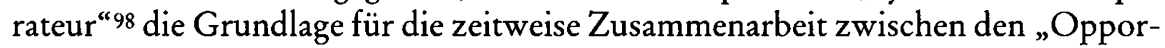
tunistes" bzw. der durch Waldeck geleiteten Regierung und den dem Klassenkampfgedanken kritisch gegenüberstehenden „syndicats modérés“ nach 1882, schließlich während der großen Streikwelle zwischen 1899 und 1901.99 Wenn auch die anvisierte Kooperation noch während der großen Streiks von Creusot, Montceau und Saint-Etienne tatsächlich zustande kam, so zeigte doch aber spätestens die Folge von Arbeitsniederlegungen ab 1904, daß die Idee der Syndikate als Ort des Ausgleichs und des Kennenlernens der Bedürfnisse der jeweils anderen Seite nicht umzusetzen war. Angesichts der zunehmenden Isolierung der „anti-sozialistischen Mustergewerkschaft[en] "100 konnten sie genausowenig wie die übrigen bürgerlich inspirierten Reformansätze den sozialen Frieden dauerhaft sicherstellen. ${ }^{101}$ Umso erstaunlicher ist es, daß Reynaud die Streikwellen der Jahre 19041909 nicht als Dementi seines Harmoniemodells begriff. Er baute vielmehr darauf, daß die französische Gewerkschaftsbewegung wie die englische nach einer notwendig unruhigen Gründungsphase zu mehr "systemkonformem“ Verhalten zurückkehren werde. ${ }^{102}$ In einem Punkt nur hielt er eine Modifikation des nicht-

${ }^{95}$ Ebenda, S. 101 f. (Zitat: S. 102).

96 "Waldeck-Rousseau pensait que l'enrichissement des ouvriers les attacherait à l'ordre social en faisant d'eux de petits bourgeois. [...] Leur donner la richesse, c'est leur donner la solvabilité, c'est créer en eux le sens de la responsabilité de leurs actes" (Ebenda, S. 103 f.).

${ }^{97}$ Sorlin, Waldeck-Rousseau, S. 244-252; Peter Schöttler, Die Entstehung der „Bourses du Travail“. Sozialpolitik und französischer Syndikalismus am Ende des 19. Jahrhunderts, Frankfurt/New York 1982, S. 42-56.

98 Sorlin, Waldeck-Rousseau, S. 250.

99 Ebenda, S. 256-298, 463-480.

100 Schöttler, Bourses du Travail, S. 53.

101 Rebérioux, République radicale?, S. 90 f.; Elwitt, Third Republic Defended, S. 297.

102 "Comme tous les organismes sociaux, les syndicats ont besoin de s'adapter à la vie et il est permis d'espérer que, tout en gagnant en puissance, ils s'assagiront comme l'ont fait les syndicats anglais, dont la création fut suivie, il y a un demi siècle de nombreux excès“ (Reynaud, Waldeck-Rousseau, S. 103). 
interventionistischen Konzepts für unausweichlich: Für den Fall drohender Generalstreiks - eine Gefahr, die im Gegensatz zu den Zeiten Waldeck-Rousseaus nun nicht mehr nur eine theoretische war ${ }^{103}$ - befürwortete er reglementierende staatliche Eingriffe im öffentlichen Interesse. ${ }^{104}$

Als bloße Ideologie zur Kaschierung von Klasseninteressen sind diese Vorstellungen nicht abzutun. Der geringe Organisationsgrad der Arbeiterbewegung in Frankreich noch zu Beginn des 20. Jahrhunderts und die Tatsache, daß der revolutionäre Syndikalismus nach 1907 zu einem stärker reformistischen Verständnis zurückgekehrt war, gab derartigen Harmonievorstellungen eine reale Basis. Die Idee von der Interessengemeinschaft des republikanischen Bürgertums mit der Arbeiterbewegung hatte sich in der Dreyfus-Affäre bewährt, und sie machte auch noch um 1911 durchaus Sinn. 105 Ungeachtet dessen sind theoretische Konzepte im biographischen Zusammenhang an ihrer Fortentwicklung und an den resultierenden Handlungen zu messen. Im Falle Reynauds ist die Bilanz eindeutig: Auch nach dem Ersten Weltkrieg gelangte der Politiker nicht zu einem den neuen Realitäten angepaßten, eigenständigen sozialpolitischen Konzept. Das Wachstum der Wirtschaft und die ökonomische Saturierung der Arbeiterschaft blieben für ihn auf Dauer die wichtigsten Remedien im Umgang mit der sozialen Frage.

Was also bedeutete es für Paul Reynaud, so kann man resümierend noch einmal fragen, Republikaner zu sein im Frankreich des frühen 20. Jahrhunderts? Es hieß zunächst einmal, überzeugt zu sein von der Reformierbarkeit der Verhältnisse, vom Gewicht der Vernunft, vom Nutzen des allgemeinen gesellschaftlichen Fortschritts und vom Wert des idealerweise entideologisierten, individuellen politischen Engagements. Konkreter bedeutete es für ihn, sein politisches Denken in der Traditionslinie der „Républicains de gouvernement“ und „Républicains modérés" vom Schlage eines Waldeck-Rousseau oder Jules Ferry zu definieren, mit den politischen Grundorientierungen, die sich damit verbanden: die demokratische, parlamentarische, laizistische, antiplebiszitäre und wehrhaft-antiextremistische Republik, sicherlich; aber auch bürgerlicher Führungsanspruch und Erhalt der Eigentumsverhältnisse, somit ein gesellschaftspolitischer Konservativismus, der die wichtigste Scheidelinie zur Linken hin bildete.

„Modéré" zu sein hieß für Reynaud, Politik zu konzipieren mit dem Anspruch auf Umsetzung eines weitgefaßten Mittelwegs zwischen „Reaktion“ und „Revolution“. Insofern enthielt seine Teleologie der Republik von 1913 zugleich in nuce ein allgemeineres Reformverständnis, das er bei allen Konkretisierungen und Anpassungen der folgenden Jahrzehnte nie aufgab. Gefahr drohte der Demokratie demzufolge in erster Linie vom potentiellen Versagen ihrer Führungsschichten oder von der freigesetzten Willkür entfesselter Massen. So galt es, durch die Wiederherstellung des überparteilichen republikanischen Konsensus, durch Weiter-

${ }^{103}$ Sorlin, Waldeck-Rousseau, S. 474.

104 Reynaud, Waldeck-Rousseau, S. 102 f.

${ }^{105}$ Hierzu in vergleichender Perspektive und mit Ausblicken auf die Organisationsgeschichte: Friedhelm Boll, Arbeitskämpfe und Gewerkschaften in Deutschland, England und Frankreich. Ihre Entwicklung vom 19. zum 20. Jahrhundert, Bonn 1992, S. 164 ff.; allgemein zur Arbeiterbewegung in Frankreich vor 1940: Roger Magraw, Workers and the bourgeois republic (A history of the French working class 2), Oxford 1992, hier: S. 3-128; Georges Lefranc, Le syndicalisme en France, Paris ${ }^{9} 1975$. 
entwicklung der Institutionen und die ökonomische Teilhabe benachteiligter Schichten den Zerfall der Nation an der politischen Malaise oder der sozialen Frage zu verhindern. Ein emphatischer, vorstaatlicher Republikbegriff sollte dafür, wie gesehen, die tragende Basis bilden, und in der Verwendung bei Reynaud schimmerte dessen Herkunft als weltanschaulich aufgeladener „Kampfbegriff“ der Revolutionszeit noch durch. Entsprechend ist Reynauds Schrift über Waldeck-Rousseau durchdrungen vom Appell an die Tugend des "civisme“, an jenen staatsbürgerlichen Gemeinsinn also, der in der liberalen Ethik seit Montesquieu als „erste Pflicht des 'citoyen'“ in den Vordergrund gerückt wurde: Die Republik hatte nicht nur in ihren Organen, sondern im gemeinschaftstragenden Verhalten jedes einzelnen Menschen gegenwärtig zu sein. ${ }^{106}$ Der erste und wichtigste Ansatzpunkt für die produktive Fortentwicklung des Bestehenden lag damit in der Überzeugungsarbeit und in der Aufklärung: Die Arbeiterschaft mußte zur Einsicht in die Erfordernisse des Ganzen und in die gegebenenfalls zu erbringenden Opfer kommen; die bürgerlichen Schichten hatten sich ihres bei Reynaud als selbstverständlich zugrundegelegten Führungsanspruchs zu erinnern und durch die Bereitschaft zum politischen Engagement und den Verzicht auf selbstsüchtige Interessenpolitik würdig zu erweisen. Der prinzipiell universelle Anspruch der Republik auf kontinuierliche Perfektionierung findet sich bei Reynaud nurmehr in gebrochener Form: Die Revolution war beendet, das Konzept der egalisierenden sozialen Umwälzung zur Domäne der sozialistischen Linken geworden. Das republikanische Erbe war durch Veränderungen innerhalb des bestehenden Systems einzulösen, im Rahmen der Verfassung und auf evolutionärem Wege. ${ }^{107}$

Während die Beschäftigung mit der sozialen Frage innerhalb der persönlichen Präferenzen Reynauds klar zurücktrat, entwickelte sich der Aspekt der Bourgeoisie-Kritik zu einem Motiv, das sich durch sein gesamtes politisches Denken und Arbeiten ziehen, an der Basis einer Reihe von Ideen und Kampagnen liegen und nicht zuletzt eine gewisse Reserviertheit begründen sollte, mit der ihm die eigene politische Klasse trotz allen immer wieder bekundeten Respekts begegnete.

Bis Jahresende 1913 allerdings handelte es sich bei diesen Ideen um nicht mehr oder weniger als die Reformvorstellungen eines bislang im wesentlichen lediglich regionalpolitisch tätigen Juristen. Mit dem Wahljahr 1914 erst ergab sich die Chance zur Bewährung auf nationaler Ebene und die Notwendigkeit zur Präzisierung des Reformwillens.

106 Burdeau, Le libéralisme, S. 113-117 (Zitat). Im deutsch-französischen Vergleich auch: Dieter Langewiesche, Republik und Republikaner. Von der historischen Entwertung eines politischen Begriffs (Stuttgarter Vorträge zur Zeitgeschichte 1), Essen 1993, hier: S. 33 (Zitat).

107 Allgemein zu den hier erwähnten Konnotationen des Republikbegriffs in Frankreich: Nicolet, L'idée républicaine, S. 441-445, 497f. Als Beispiel für eine moderne Interpretation, die das Ende der Revolution mit der Festigung der Dritten Republik ansetzt: François Furet, Penser la Révolution française, Paris 1978, hier: S. 17. Zum Reformbegriff: Eike Wolgast, Reform, Reformation, in: Geschichtliche Grundbegriffe. Historisches Lexikon zur politisch-sozialen Sprache in Deutschland. Hg. v. Otto Brunner, Werner Conze und Reinhard Koselleck, Stuttgart 1984, S. 313-360, bes. S. 344. 


\section{b) Die erste Bewerbung um ein Abgeordnetenmandat im Frübjabr 1914}

Die Wahlkämpfe liberaler Politiker der französischen Zwischenkriegszeit wurden bislang in der Forschung noch kaum systematisch in den Blick genommen. ${ }^{108} \mathrm{Im}$ folgenden soll deshalb anhand der frühen Kampagnen Reynauds bis zu seiner Etablierung als Abgeordneter des zweiten Pariser Arrondissements im Jahre 1928 deren praktischer Ablauf und programmatische Gestaltung exemplarisch untersucht werden. Damit wird es insbesondere möglich sein, Mechanismen der Wahlpromotion zu studieren, das Verhältnis von weltanschaulichen, sachpolitischen und taktischen Motivationen abzuwägen, den postulierten politischen Individualismus des Protagonisten Reynaud näher zu bestimmen und nicht zuletzt - am Beispiel der Nachwahlen von 1926 - die bekannt geringe Kohäsion im rechtsliberalen Milieu konkreter als bisher festzumachen. ${ }^{109}$

Paul Reynauds erste Bewerbung um ein Abgeordnetenmandat auf nationaler Ebene - er war seit August 1913 bereits Conseiller Général für den Canton SaintPaul in seinem Heimatdépartement Basses-Alpes 110 - verlief unter denkbar ungünstigen Umständen. Ohne genauere persönliche Kenntnis des Wahlkreises und seiner politischen Gegner, ohne Gelegenheit zur eingehenden Vorbereitung seiner Kampagne, trat er im April 1914 in der erhitzten Atmosphäre eines Wahlkampfes an, der unter dem Vorzeichen der zähen und langwierigen Debatte um die Reform der französischen Wehrverfassung stand.

Im Juli 1913 war in der Kammer der Abgeordneten nach monatelanger öffentlicher Diskussion ein Gesetz zur Verlängerung des Wehrdienstes von zwei auf drei Jahre verabschiedet worden. Seitens der zivilen und militärischen Führung in erster Linie mit der Gefahr eines deutschen Überraschungsangriffs begründet, in Wahrheit jedoch Ergebnis längerfristiger strategischer und bündnispolitischer Überlegungen, war das Projekt auf erheblichen Widerstand im internationalistisch orientierten sozialistischen und auch im linksrepublikanischen Milieu gestoßen. Dort vertrat man eine andere Verteidigungskonzeption und interpretierte die geplante Vergrößerung des stehenden Heeres als Symptom einer bevorstehenden „reaktionären Wende“ in der Innenpolitik des Landes. Das geschickte Vorgehen der Regierung Barthou, die unter anderem eine baldige Rücknahme der Regelung in Aussicht stellte und versprach, im Zusammenhang der Armeereform die im Lager der Linken und der linken Mitte seit langem geforderte Neuregelung des Steuerwesens in Angriff zu nehmen, hatte die Verabschiedung des Gesetzes mit den Stimmen auch eines bedeutenden Teils der linksrepublikanischen Abgeordneten ermöglicht. Im Wahlkampf von 1914 stand die Frage erneut auf der Tagesordnung, da sich in der Radikalen Partei, dem numerisch stärksten Träger der Neuregelung im Parlament, das Kräfteverhältnis zwischen Gegnern und skeptischen Befürwortern des Kompromisses zugunsten ersterer neu eingependelt hatte. So

108 Für die achtziger Jahre des 19. Jahrhunderts: Elfi Bendikat, Wahlkämpfe in Europa 1884-1889. Parteiensysteme und Politikstile in Deutschland, Frankreich und Großbritannien, Wiesbaden 1988; auf Parteiebene bietet für die Jahrzehnte zwischen den Weltkriegen vereinzelte Hinweise: Berstein, Parti radical I und II, passim.

109 Siehe dazu auch unten die Kapitel V.1, VI.1 und VI.3.

10 Vgl. hierzu die Wahlaufrufe Reynauds: „Elections au Conseil Général du 3 août 1913. Aux Electeurs du Canton de Saint Paul“" (AN, 74 AP 8). 
hatte sich die Parteileitung genötigt gesehen, während des Parteikongresses von Pau im Oktober 1913 ein „Minimalprogramm" verabschieden zu lassen, in das die Rückkehr zur zweijährigen Wehrpflicht wenn auch nicht als verbindliches, so doch als langfristig anzuvisierendes Ziel aufgenommen worden war. Nicht zuletzt diese fluktuierende Haltung der Radicaux, die zudem im Dezember 1913 mit dem Ministerium Doumergue an die Regierung gelangt waren, hatte zur Bildung einer „liberal-konservative[n] Sammlungsbewegung“, der "Fédération des Gauches“ unter Briand und Barthou geführt. Sie hatte sich gleichermaßen die Verteidigung des Wehrgesetzes und die Bekämpfung der durch die radikale Partei anvisierten Steuerreform auf ihre Fahnen geschrieben. ${ }^{111}$

Ohne parteipolitisch vorbelastet zu sein, erhielt Paul Reynaud im Frühjahr 1914 unter der klaren Vorgabe, für die Verteidigung der „Loi de trois ans“ einzutreten, die Chance zur Kandidatur um einen Sitz in der Chambre des Députés. Seit seinem effektvollen Auftreten als Erster Sekretär der Anwaltskammer hatte für den jungen Juristen der berufliche, gesellschaftliche und private Erfolg nicht auf sich warten lassen. Klug hatte er es vermieden, die Konfrontation auf die Spitze zu treiben, hatte es bei der öffentlichkeitswirksamen Geste unabhängiger Denkart bewenden lassen und die zunächst hartnäckig für einen erweiterten Rahmen außerhalb des „Palais“ angekündigte Rede zu Ehren Waldeck-Rousseaus erst nach Verebben der Unmutswogen publik gemacht. Seit Oktober 1911 als Anwalt an der Pariser "Cour d'assises“, dann am Appellationsgerichtshof tätig, hatte er - seiner Würde als preisgekrönter Gerichtsredner und seinem rasch erworbenen Ruf als vielversprechendes Nachwuchstalent entsprechend - unmittelbar Gelegenheit erhalten, in aufsehenerregenden Fällen von Mord und Bandenwesen zu plädieren. ${ }^{112}$ Der durchaus wechselhafte Erfolg seiner Tätigkeit als Strafverteidiger tat der wachsenden Achtung keinen Abbruch, die man ihm in Pariser Juristenkreisen entgegenbrachte ${ }^{113}$ und die ihm ab Sommer 1912 die Mitarbeit an einer juristischen Kolumne im Feuilletonteil von "Le Temps" eingetragen hatte. ${ }^{114}$ Seine Heirat mit der Tochter des einflußreichen Anwalts und späteren Präsidenten der $\mathrm{Pa}$ riser Anwaltskammer, Henri-Robert, im Februar 1912 als großes gesellschaftliches Ereignis in Szene gesetzt, hatte ihm endgültig Eintritt in führende juristische,

$11 \mathrm{Zu}$ den Debatten um die „Loi de Trois Ans“ im Überblick: Krumeich, Aufrüstung und Innenpolitik, S. 272-281 (Zitat: S. 279). Zur Diskussion der Frage im Vorfeld der Wahlen von 1914 auch: Jean-Jacques Becker, 1914: Comment les Français sont entrés dans la guerre. Contribution à l'étude de l'opinion publique, printemps-été 1914, Paris 1977, S. 62-83. Serge Berstein geht in seiner Überblicksstudie kaum auf die Haltung des Parti Radical zur Frage der Wehrverfassung ein: Berstein, Parti Radical I, S. 77.

112 Vgl. Reynaud, Mémoires I, S. 94-99; „Renseignements concernant Paul Reynaud extraits de son dossier individuel“ (Archives de l'Ordre des avocats à la Cour de Paris).

113 In seinem ersten Mordprozeß konnte Reynaud die Verurteilung des Angeklagten zum Tode nicht verhindern (Reynaud, Mémoires I, S. 94 f.). Vgl. dagegen die Sammlung von Gratulationsschreiben, die Reynaud im Februar 1913 nach seiner erfolgreichen Prozeßführung für den Anarchisten Reinert zugingen, u.a. von Paul Cresson, César Campinchi und Jean Bardoux: „[...] Je n'y était pas, malheureusement pour moi - mais l'écho du Palais qui est bien plus qu'un affectueux témoignage d'un ami, m'est parvenu et tu l'auras entendu déjà toi aussi. Tu as eu un très beau succès. Je m'en réjouis sans en être surpris le moins du monde. [...]" (Bardoux an Reynaud, undatiert, vermutlich Februar 1913; AN, 74 AP 6).

114 Unter der Rubrik „La vie et le droit“ stellte Reynaud in unregelmäßigen Abständen Rechtsfälle vor und gab juristische Ratschläge in unterhaltsamer Form (vgl. Le Temps vom 7. 7., 28. 7., 13. 9., 13. 10., 17. 11., 24. 12. 1912, vom 9. 2., 1.6., 1. 7., 31.8., 28. 11.1913 und 14. 4. 1914). 
intellektuelle und politiknahe Kreise verschafft. ${ }^{115}$ Darüber hinaus unterhielt Reynaud teils verwandtschaftlich begründete Verbindungen zu Honoratiorenkreisen in seiner Heimatregion, die seiner politischen Karriere eindeutig zugute kamen. So war bereits seine Wahl zum Conseiller Général durch die wohlwollende Unterstützung eines Onkels, des Bankiers und ehemaligen Senators des Départements Basses-Alpes, Adrien Gassier, nachhaltig gefördert worden. Für die neuerliche Kandidatur bahnte die Vermittlung und Wahlkampfhilfe eines Senators der Hautes-Alpes, Balthazar Blanc, den Weg. ${ }^{116}$

Reynaud trat als Ersatzkandidat an, durch den der „parti modéré“ des Départements das „désistement" seines Bewerbers gegenüber dem erfolgreicheren radikalsozialistischen Kandidaten aufzufangen versuchte, nachdem dieser im ersten Wahlgang vom 26. April knapp ein Drittel der Wählerstimmen auf sich hatte vereinen können. Die geringen Chancen, gegen den Radikalen zu bestehen, der das Département bereits zwei Jahre als Abgeordneter vertreten hatte, hatten Reynaud vor dem ersten Durchgang auf die angetragene Bewerbung verzichten lassen. Auch im Vorfeld des zweiten Wahlgangs jedoch verfügte er im wesentlichen nur über indirekt wirksames Kapital: die Protektion des amtierenden Senators des Départements, der ihn auf seiner kurzen Wahlkampfreise begleitete, die guten geschäftlichen Beziehungen seines Onkels in die Region und schließlich die Schwungkraft der Ideen, die er vertrat. Den unter dem geltenden Persönlichkeitswahlrecht mitentscheidenden „Standortvorteil“ des engen persönlichen Kontakts zur Wählerschaft konnte der im Département völlig unbekannte Pariser Anwalt kaum mehr für sich erschließen.117

Wenn die radikale Partei traditionell im äußersten Südosten Frankreichs, im Rhônetal und im mittelmeerischen Süden eine eher schwache Stellung einnahm, so bildete das Département Hautes-Alpes hiervon eine bemerkenswerte Ausnahme. ${ }^{118}$ Die Bevölkerung hatte sich zudem anläßlich der sozialistischen Petiti-

115 Zum Empfang anläßlich der Hochzeitsfeierlichkeiten war nahezu das gesamte „Palais“ vertreten, ein eindrucksvoller Ordnungsdienst mühte sich um die Bändigung der Menschenmassen: vgl. „Le Barreau marie sa fille", in: Le Cri de Paris, Februar 1912.

116 „M. Reynaud, originaire de Barcelonnette (Basses-Alpes), est neveu de M. Gassier, banquier en cette ville, ancien député et sénateur des Basses-Alpes. C'est grâce à l'influence très grande de son parent, que M. Reynaud est devenu, l'an dernier, conseiller général dans ce département. [...]“ („Département des Hautes Alpes. Elections législatives du 26 avril 1914.“ - Präfektenbericht an das Innenministerium, 5. 5. 1914; Archives Départementales des Hautes-Alpes (künftig: AD Hautes-Alpes), 3 M 242). In den entsprechenden Abschnitten seiner Memoiren schweigt sich Reynaud über diesen Aspekt seines politischen Fortkommens weitgehend aus: Reynaud, Mémoires I, S. 102-104.

117 „[...] C'est à raison, également, des relations qu'entretient M. Gassier, nommé banquier, dans le départt des $\mathrm{H}^{\text {tes }}$ Alpes, que $\mathrm{M}$. Reynaud a songé à se présenter dans l'arr ${ }^{\mathrm{t}}$ de $\mathrm{Gap}$ où, personnellement, il était complèt $t^{t}$ inconnu, jusqu'à ces dernières semaines. [...]" (Präfektenbericht an das Innenministerium, 5. 5. 1914; AD Hautes-Alpes, 3 M 242). Nur 10 Tage vor Durchführung der zweiten Abstimmungsrunde hatte sich Reynaud in einer knapp gehaltenen, an die Wähler des Kreises adressierten Wahlkampfbroschüre vorgestellt und zu persönlichem Kennenlernen im Beisein des Senators Blanc gebeten (30. 4. 1914; AD Hautes-Alpes, 3 M 242).

In einem Rundbrief an die Wählerschaft bat ein amtierender Conseiller Général darum, „Aktivität" und "Einfluß $\aleph^{\prime}$ zugunsten der Kandidatur Reynauds zu entfalten. Beigefügt waren zwei Wahlzettel auf den Namen Reynaud (Auguste Tourrès, Rundbrief v. 7. 5. 1914; AD Hautes-Alpes, $3 \mathrm{M}$ 242). Zu den Umständen der Aufstellung Reynauds und zu den Beziehungen des Senators Gassier im Département vgl. den Präfektenbericht v. 30. 4. 1914 (AD Hautes-Alpes, 3 M 242).

118 Berstein, Parti Radical I, S. 84. 
onskampagne vom Frühjahr 1913 als überdurchschnittlich mobilisierbar gegen die "loi de trois ans" erwiesen, und dies, obwohl die SFIO von ihrem Mitgliederstand her im Département nur unterdurchschnittlich präsent war.119

Offiziellerseits als der „Fédération des Gauches“ nahestehend betrachtet ${ }^{120}$ und von der radikalsozialistischen Presse als „Briandiste“ angesprochen ${ }^{121}$, trat Reynaud als unabhängiger republikanischer Kandidat unter dem vagen Etikett des „Républicain de Gauche" auf. ${ }^{122}$ Er berief sich damit auf eine reputierte Gruppierung, die in der Chambre des Députés neben der "Gauche démocratique" traditionell als wichtigster Sammlungsort der rechts vom „Parti Radical“ stehenden parlamentarischen Mitte auftrat. ${ }^{123}$ Wie bereits im Vorfeld seiner Kandidatur vermutet worden war ${ }^{124}$, präsentierte er sich über eine klar republikanisch ausgerichtete "profession de foi“, ohne sich zum Wahlprogramm einer der bestehenden politischen Parteien zu bekennen. Als ein der „Alliance Républicaine Démocratique" nahestehender Politiker ist Reynaud erst gegen Jahresende $1921 \mathrm{faßbar}$, als er am Parteitag der Gruppierung intervenierte. ${ }^{125}$ Ein Bekenntnis zu dieser Gruppierung wäre nach deren Rechtswendung im Vorfeld der Wahlen in der konkreten Situation auch politisch wenig opportun gewesen und hätte zweifellos der Taktik der radikalsozialistischen Partei in die Hände gearbeitet. Diese betrieb den Wahlkampf auch im Département unter dem Anspruch, die Werte der laizistischen Republik gegen jene "reaktionäre“ Koalition aus Anhängern der "Loi de trois ans“ zu verteidigen, zu der sich traditionell konservative Gruppen mit eher gemäßigten Kreisen zusammengefunden hätten. ${ }^{126}$

So war Reynaud in seinem Wahlprogramm spürbar bemüht, jeden Verdacht illiberaler Gesinnung von vorneherein zu entkräften, mehr noch, auch linksliberalen Wählern Möglichkeiten zur Identifizierung zu bieten. Er stellte die „Loi de trois ans" in den Mittelpunkt seines Wahlkampfes und übernahm die gängige Argumentation ihrer Befürworter vom drohenden deutschen Überraschungs-

119 Krumeich, Aufrüstung und Innenpolitik, S. 75-77. Nach seinen Berechnungen ergibt sich für das Département Hautes-Alpes ein Verhältnis zwischen Bevölkerungszahl und Anzahl der eingereichten Petitionen von 186:1; angesichts eines Durchschnittswerts von 1453:1 für die Gruppe der Départements, die bezüglich der Präsenz der SFIO als vergleichbar angesetzt werden konnten, kann also eine bemerkenswerte "Ansprechbarkeit der Bevölkerung" für die Kampagne festgestellt werden. Die geschätzte Mitgliederzahl der SFIO im Département betrug dagegen unter 100, was die Region im nationalen Vergleich im untersten Bereich rangieren ließ (Ebenda, S. 76, Anm. 97).

120 Präfektenbericht, 5. 5. 1914; AD Hautes-Alpes, 3 M 242.

121 Les Alpes Républicaines, 11. 5. 1914.

122 Wahlbroschüre Reynauds, 30. 4. 1914; AD Hautes-Alpes, 3 M 242.

${ }^{123}$ Krumeich, Aufrüstung und Innenpolitik, S. 233.

124, „...] Je vous fixerai, dès que j'en aurai connaissance, sur l'étiquette politique que prendra M. Reynaud. Il est vraisemblable que, par tactique électorale, il va établir une profession de foi nettement républicaine." (Präfektenbericht, 30. 4. 1914; AD Hautes-Alpes, 3 M 242).

125 Vgl. La République Démocratique, 25. 12. 1921. Das genaue Eintrittsdatum in die "Alliance“ ist nicht mehr festzustellen. Auch die noch für die Benutzung gesperrte Personalkartei der Partei scheint hierüber aber keine Informationen zu bieten (Mitteilung der Handschriftenabteilung der Pariser Nationalbibliothek an den Verfasser, 23. 10. 1995).

126 Vgl. dazu die Stellungnahme des "Comité Exécutif" des Parti Radical zu den bevorstehenden Wahlen, in: Le Radical, 12. 4. 1914; dazu auch Krumeich, Aufrüstung und Innenpolitik, S. $222 \mathrm{f}$. Zur entsprechenden Argumentation des radikalsozialistischen Kandidaten im Département Hautes-Alpes, Victor Peytral, vgl. etwa "Victoire Républicaine“, in: Les Alpes Républicaines, 11. 5. 1914. 
angriff ${ }^{127}$, hütete sich aber vor nationalistischen Übertreibungen. Mit der Forderung nach baldmöglicher Wiederabschaffung setzte er sich zudem klar vom dogmatischeren Standpunkt der „Fédération des Gauches“ ab, was ihn aber nicht hinderte, sich in diesem Zusammenhang auf deren Führer Briand und Barthou ebenso zu berufen wie auf den radikalsozialistischen Regierungschef Doumergue, der sich in seiner Antrittserklärung zu loyaler Ausführung des verabschiedeten Wehrdienstgesetzes bereit gezeigt hatte. 128

Eine ähnliche Gratwanderung zwischen rechts- und linksrepublikanischen Positionen vollführte Reynaud in der Frage der Reform des Steuerwesens, die nach Amtsantritt der Regierung Doumergue und unter Federführung des Finanzministers Caillaux wieder zu einem tagespolitischen Thema ersten Ranges avanciert war. Im Jahre 1909 durch die Deputiertenkammer beschlossen, war die Modernisierung des in seinen Grundzügen noch auf den Regelungen der Französischen Revolution beruhenden Einkommensteuersystems bis dahin am Widerstand des Senats gescheitert. Der Vorschlag Caillaux' auf Einführung einer Kapitalsteuer nicht zuletzt zur Finanzierung der geplanten Aufrüstungsmaßnahmen hatte die Debatte im Januar 1914 neu entfacht, zumal das von ihm unterstützte Kammergesetz ebenfalls vorwiegend die begüterteren Schichten zur Finanzierung der kommenden finanzpolitischen Lasten heranzuziehen drohte. Ende März 1914 hatte die Kammer trotz einer heftigen Kampagne in der konservativen Presse, die mit Caillaux die allgemeine Linksbewegung der französischen Innenpolitik zu treffen versucht hatte, mit großer Mehrheit dem Kern der Einkommensteuerreform zugestimmt. Damit war nicht nur die relativ stärkere Belastung der vermögenden Schichten festgeschrieben, sondern überdies das Prinzip der progressiven Steigerung des Steuersatzes und die Pflicht zur Offenlegung der Einkommensverhältnisse in das französische Steuersystem eingeführt worden. ${ }^{129}$

Reynaud zeigte wiederum wenig Berührungsängste gegenüber der radikalsozialistisch inspirierten Steuerreform, die in der öffentlichen Diskussion von konservativer Seite als Fanal des Systemsturzes verunglimpft und immerhin auch durch die „Fédération des Gauches“ noch vor Beginn des Wahlkampfes als zum gegebenen Zeitpunkt verfrüht abgelehnt worden war. ${ }^{130}$ Klar trat er für die Einführung der Einkommensteuer in der kommenden Legislaturperiode ein und

127 Nach eigenen Angaben durch eine Rede Louis Barthous von der drohenden deutschen Gefahr überzeugt, veranschaulichte Reynaud seine Kampagne für die Beibehaltung der Wehrdienstverlängerung in den Wahlversammlungen durch die Demonstration des deutschen Angriffsplanes über belgisches Territorium (Reynaud, Mémoires I, S. 103 f.).

128 „Je crois comme les ministères Poincaré, Briand, Barthou et Doumergue que la loi de trois ans est indispensable à la défense du territoire: c'est la rançon de la paix. Si les circonstances le permettent un jour, je serai des premiers à demander l'allègement de ce lourd fardeau. [...]" (Paul Reynaud, „Aux Electeurs de l'Arrondissement de Gap“, April/Mai 1914; AD Hautes-Alpes, 3 M 243).

Zur Regierungserklärung Doumergues vgl. Krumeich, Aufrüstung und Innenpolitik, S. 175-178.

129 Der Senat verabschiedete das Gesetz Mitte Juli 1914; Ende März hatte die Finanzkommission der Abgeordnetenkammer zudem Caillaux' Kapitalsteuerprojekt in seinen großen Linien übernommen. Der Ausbruch des Ersten Weltkriegs verhinderte die Verabschiedung und Anwendung der Reform.

$\mathrm{Zu}$ den Debatten um und den Hintergründen der Steuerdiskussion vgl. Krumeich, Aufrüstung und Innenpolitik, S. 187-218. Zur Vorgeschichte auch: Rudolf von Albertini, Die Diskussion um die französische Steuerreform, 1907-1909, in: Schweizer Beiträge zur allgemeinen Geschichte 13 (1955), S. 183-201.

130 Dazu Krumeich, Aufrüstung und Innenpolitik, S. 210 f. 
befürwortete in verklausulierter Form auch die zu diesem Zeitpunkt noch nicht verabschiedete Steuer auf Kapitalerträge. Diese Zustimmung zur Steuerreform, die er, wie sich gezeigt hatte, mit einer weit in die Mitte reichenden parlamentarischen Mehrheit teilte, ist als Tatsache allein weniger interessant als die Art und Weise, in der er sein Engagement mit ,antikapitalistischer" Argumentation verband. ${ }^{131}$ Der Gedanke lag in der Luft, seit der Vorgänger Doumergues' im Amt des Regierungschefs, Louis Barthou, versprochen hatte, zur Aufbringung der Kosten der "Loi de trois ans" besonders die vermögenderen Schichten heranzuziehen. Reynaud nutzte die Diskussion, um sich als Verteidiger der Interessen der "classe moyenne" zu stilisieren. Sein Vorgehen implizierte nicht nur die Wendung gegen die härtesten organisierten Gegner der finanzpolitischen Neuregelungen wie die führenden Wirtschaftsverbände und die Handelskammern. ${ }^{132}$ Er zeigte sich überdies unbeeindruckt von der ungemein heftigen Kampagne, die seit Anfang Januar 1914 nahezu in der gesamten bürgerlich-gemäßigten und rechten Presse unter dem Vorzeichen des Systemerhalts und der Verteidigung sozio-ökonomischer Besitzstände gegen die Steuerpolitik der Regierung Doumergue/Caillaux geführt worden war. ${ }^{133} \mathrm{Im}$ Hinblick auf die Kluft, die sich in dieser Frage zwischen bürgerlicher Interessenpolitik und öffentlicher Meinung auftat, hatte sich Reynaud für die zweifellos populäre Forderung nach mehr Steuergerechtigkeit zum baldmöglichsten Zeitpunkt entschieden. Daß er mit der Ablehnung der Deklarationspflicht für Einkommen einen zentralen Kritikpunkt der Reformgegner aufgriff, änderte nichts daran, daß er sich durch seine Thesen gegen die erklärten Interessen der „besitzenden Schichten“ exponiert hatte. Der Programmpunkt verrät sicherlich ein gerüttelt $\mathrm{Maß}$ an wahltaktisch begründetem Entgegenkommen gegenüber der radikalsozialistischen Klientel seines Gegners; er stellt aber auch die logische Fortsetzung der Bourgeoisie-Kritik dar, die Reynaud im Vorjahr so vehement vorgetragen hatte. Diese war in der Tat kein beliebiges Accessoire in einer für gewöhnlich eher wenig aussagekräftigen "profession de foi“. Sie war mehr noch eine Denkfigur, die sich zu einem Leitmotiv des politischen Handelns Reynauds entwickeln sollte. Dies gilt in ähnlicher Weise für weitere seiner programmatischen Festlegungen: Sowohl die Idee der Einführung eines „scrutin élargi avec représentation des minorités", also des Verhältniswahlrechts, wie auch seine Vorschläge zur Revision der Verfassung im Sinne einer Beschleunigung der parlamentarischen Arbeit prägten im Kern bereits seine Hommage an WaldeckRousseau und beschäftigten ihn im Verlaufe seines politischen Lebens bei durchaus unterschiedlicher Akzentsetzung wiederholt.

Der Vergleich der Wahlkampfprogramme Reynauds und seines wichtigsten Gegners Peytral zeigt darüber hinaus, daß die Unterschiede zwischen den Positionen bei Nähe besehen bedeutend weniger groß waren, als dies von beiden in ihren

131 „[...] Il est indispensable que l'impôt sur le revenu soit voté par la prochaine législature. Mais je suis l'adversaire de la déclaration contrôlée qui entraînerait l'inquisition fiscale, la violation du secret des familles et des affaires et finalement la faillite de cette réforme. J'estime que la réforme fiscale ne doit pas être un moyen d'oppression de la classe moyenne au profit des capitalistes qui pourraient se soustraire à l'impôt par l'émigration des capitaux.“ (Paul Reynaud, „Aux Electeurs de l'Arrondissement de Gap“, April/Mai 1914; AD Hautes-Alpes, 3 M 243).

132 Krumeich, Aufrüstung und Innenpolitik, S. $208 \mathrm{f}$.

133 Zur Pressekampagne vgl. Ebenda, S. 209-218. 
Wahlkampfpublikationen dargestellt wurde. Das gilt für die Stellung zum Wehrgesetz, hinsichtlich dessen sich der Radikalsozialist auf den Formelkompromiß des Parteikongresses von Pau berief und Reynaud eine klare, aber nicht dogmatische Position einnahm ebenso wie für das Steuerproblem, in dessen Behandlung Reynaud sich dem radikalen Standpunkt annäherte. Die in der Forschung lange thematisierte, vermeintlich dramatische Blockbildung im Wahlkampf von 1914 zwischen der Linken und der Rechten, zwischen Gegnern und Anhängern der "Lois de trois ans" fand im Département Hautes-Alpes nicht statt. Die Position Reynauds ist ein schlagendes Beispiel dafür, daß von der durch die zeitgenössische extreme Linke und Rechte postulierten zwangsläufigen Koppelung der verteidigungspolitischen Option für das Wehrgesetz und der "reaktionären“ Ablehnung der Steuerreform selbst für den Wahlkampf nicht-radikaler Republikaner nicht gesprochen werden kann. ${ }^{134}$ Die schwach ausgeprägte Parteidisziplin und die geringe Bindekraft von ad hoc gebildeten Wahlhilfskomitees republikanischer Kandidaten favorisierten die Ausformung persönlicher Programmatiken. Im Falle Reynauds resultierte daraus eine „profession de foi“, die sehr viel deutlicher von der unabhängigen Beurteilung von Sachfragen und der taktischen Rücksichtnahme auf die Wählerschaft als von der bewußten Unterordnung unter eine „linke“ oder „rechte“ Doktrin zeugte.

Entsprechend dem nationalen Trend knapp fiel das Ergebnis des zweiten und entscheidenden Wahlganges aus. Zwar wurde Reynaud um über tausend Stimmen geschlagen, doch gelang es ihm in immerhin 5 von 14 Cantons des Arrondissements, darunter im Hauptort Gap, die Stimmenmehrheit zu erlangen. ${ }^{135}$ Diese von außenstehenden Beobachtern erstaunlich exakt vorhergesagte Niederlage ${ }^{136}$ kann nicht darüber hinwegtäuschen, daß Reynaud in der Region in ein dauerhaftes und sich fortspinnendes Netz persönlicher Solidaritäten eingebunden war, das selbst Wahlen auf nationaler Ebene nahezu Kooptations-Charakter verlieh. So wie sich seine beiden Onkel Aimé und Adrien Gassier als „Kandidatenmacher“ des Départements Basses-Alpes hervorgetan und die Wahl unter anderem des späteren Erziehungs- und Kultusministers André Honnorat entscheidend befördert hatten ${ }^{137}$, so unterstützte der gleichermaßen begünstigte Reynaud 1914 selbst die Kandidatur seines Freundes Honnorat im Nachbardépartement. Im Jahre 1919 leistete der installierte Abgeordnete Honnorat dann umgekehrt Reynaud Wahlhilfe, als dieser sich im Département Basses-Alpes erneut um ein Mandat be-

${ }_{134}$ Dieser Befund stützt die Kritik Gerd Krumeichs an der „Polarisierungs-These" u.a. in den Arbeiten von François Goguel, Georges Bonnefous und Jean-Jacques Becker (Krumeich, Aufrüstung und Innenpolitik, S. $219 \mathrm{f}$.; dort auch genauere Nachweise zu den kritisierten Textstellen).

135 Reynaud unterlag mit 5803 gegen 7217 Stimmen seines Konkurrenten. Zu den Ergebnissen des zweiten Wahlgangs vom 10. Mai 1914 vgl. Georges Lachapelle, Elections législatives des 26 avril et 10 mai 1914, Paris 1914; Les Alpes Républicaines, 11. 5. 1914.

136 In seinem Resümee nach dem ersten Wahlgang hatte der Präfekt bereits die Prognose abgegeben, daß Reynaud durch seinen Gegner um über tausend Stimmen geschlagen werden würde (Präfektenbericht, 30. 4. 1914; AD Hautes-Alpes, 3 M 242).

137 „[...] Ils eurent, pendant toute leur vie, son frère Aimé et lui [Adrien Gassier; A.d.V.], tous deux conseillers généraux, une influence politique qui alla jusqu'à faire élire député de Barcelonnette un chroniqueur parisien, Henry Fouquier [...]. Ils eurent la main plus heureuse en choisissant ensuite un homme de valeur, Paul Delombre qui fut ministre du commerce. [...] Paul Delombre battu, ils firent ensuite élire mon ami André Honnorat [...]" (Reynaud, Mémoires I, S. 28 f.) 
warb. ${ }^{138}$ Die „Berufung“ Ortsfremder war dabei wie im Falle Reynauds kein Einzelereignis, sondern besonders in den alpinen Départements des französischen Südostens durchaus an der Tagesordnung. Das Interesse ambitionierter Kandidaten an einem „aufnahmebereiten" Wahlkreis traf sich hier mit dem Wunsch lokaler Honoratioren nach einem einflußreichen bzw. immerhin vielversprechenden Bewerber oder dem Bestreben regionaler Eliten, örtliche Konkurrenten durch die Einführung außenstehender "parachutés" auszustechen, welche dann wiederum ihren Förderern verpflichtet sein würden. ${ }^{139}$

Trotz der vorhersehbar geringen Erfolgsaussichten scheint Reynaud seine Niederlage nicht ohne Enttäuschung aufgenommen zu haben. In einer Dankesadresse an seine Wähler konstatierte er mit bitterem Unterton, als „Fremder" denunziert worden zu sein, und beklagte sich über „unwürdige“ Eingriffe der Verwaltung zugunsten des radikalsozialistischen Gegners. ${ }^{140}$ Bald jedoch sollten für den ambitionierten Jungpolitiker andere und bedeutendere Umstände privater und überpersönlicher Art in den Vordergrund seines Interesses treten. So galt es im Frühjahr 1914 zunächst, die Verwaltung des nicht unbedeutenden Erbes zu regeln, das nach dem Tod des Vaters Alexandre Reynaud am 15. Dezember 1913 der Witwe und den vier Kindern zugefallen war, ohne daß durch testamentarische Verfügung das weitere Schicksal des in Mexiko und Paris ansässigen Familienunternehmens bereits bestimmt gewesen wäre. ${ }^{141}$ Mit dem Ausbruch des Ersten Weltkriegs und dem frühen Tod des älteren Bruders Albert, der als Nachfolger in der Geschäftsleitung vorgesehen gewesen war, sah sich Reynaud neuen familiären Problemen gegenüber. Ihm erwuchs daraus die zusätzliche Bürde, als neues Oberhaupt der Familie insbesondere für deren finanzielle Belange Vorsorge treffen zu müssen. ${ }^{142}$

Zunächst aber forderte der Krieg auch von ihm seinen Tribut. Ab dem ersten Tag mobilisiert, blieb er bis April 1919 Soldat, war an der Westfront eingesetzt und bereiste in besonderer Mission den russischen Kriegsschauplatz.

138 Vgl. den durch Reynaud mitunterzeichneten Wahlaufruf zugunsten André Honnorats: „Elections législatives du 26 avril 1914. Aux Electeurs de l'Arrondissement de Barcelonnette“, in: Journal de Barcelonnette, 22. 4. 1914. Zur Bewerbung Reynauds im November 1919 vgl. Kapitel V.1 dieser Arbeit.

139 Vgl. Le Béguec, L'entrée au Palais-Bourbon, S. 582 f. Eine systematische Untersuchung des Phänomens steht noch aus, allerdings scheint eine ähnliche Situation auch in den Départements Lot und Corrèze zu beobachten gewesen zu sein. Für das Département Alpes-Maritimes wurden die Beziehungen zwischen ortsfremden Kandidaten und lokalen Eliten genauer untersucht durch die Arbeiten von Jacques Basso, u.a.: Ders., Les élections législatives dans le département des AlpesMaritimes 1860-1939, Paris 1968.

140 Das Dankschreiben Reynauds an seine Wähler findet sich abgedruckt in:Journal de Barcelonnette, 17. 5. 1914.

141 Vgl. dazu etwa den Brief Reynauds an seinen mexikanischen Anwalt Uribe vom 11. 5. 1916 (AN, 74 AP 6). Nach einer Aufstellung des Notars der Familie belief sich das Gesamtvermögen Alexandre Reynauds auf knapp eine Million Francs, genau auf 976842 Francs 80 Centimes („Notoriété après le décès de M. Reynaud Alexandre“, 12.6. 1914; ebenda).

142 Reynaud, Mémoires I, S. 109. 